\title{
The Effects of Information on Strategic Investment and Welfare*
}

\author{
Jacco J.J. Thijssen ${ }^{\dagger} \quad$ Kuno J.M. Huisman ${ }^{\ddagger} \quad$ Peter M. Kort ${ }^{\S}$
}

October 2003

\begin{abstract}
A model is considered where two firms compete in investing in a risky project. At certain points in time the firms obtain imperfect information about the profitability of the project. We impose that investing first can be beneficial because a Stackelberg advantage, and thus a higher market share, is obtained. On the other hand, investing as second implies that one can benefit from an information spillover generated by the investment of the other firm. Consequently, in equilibrium there is either a preemption situation or a war of attrition. In case no investment takes place during the war of attrition, this war of attrition can turn into a preemption situation. One counterintuitive result is that welfare can be negatively affected by signals becoming more informative or by occurring more frequently. Furthermore, simulations indicate that duopoly leads to higher welfare than monopoly when signals are less informative, whereas the opposite holds if there is more or better information.
\end{abstract}

Keywords: Uncertainty, Strategic investment, Imperfect information, Welfare. JEL codes: C61, D43, D81.

${ }^{*}$ Dolf Talman is acknowledged for many inspiring discussions and meticulous proof-reading. Jan Boone and Thomas Sparla are thanked for helpful comments. The usual disclaimer applies.

${ }^{\dagger}$ Department of Economics, Trinity College, Dublin, Ireland.

${ }^{\ddagger}$ Centre for Quantitative Methods, Eindhoven, The Netherlands.

${ }^{\S}$ Corresponding author. Department of Econometrics \& Operations Research and CentER, Tilburg University. P.O. Box 90153. 5000 LE Tilburg, The Netherlands. E-mail: Kort@uvt.nl, and Department of Economics, UFSIA, University of Antwerp, Antwerp, Belgium. 


\section{Introduction}

Two main forces that influence a firm's investment decision are uncertainty about the profitability of the investment project and the behaviour of potential competitors, having an option to invest in the same project. In this paper the influence of uncertainty and competition on the strategic considerations of a firm's investment decision and the resulting welfare effects are investigated.

The framework we use here assumes imperfect information that arrives stochastically over time. As to the project only two states are possible: either the project is profitable or it yields a loss. Firms have an identical belief in the project being profitable. This belief is updated over time due to information that becomes available via signals that arrive according to a Poisson process. The signal can either be good or bad: in the first case it indicates that the project is profitable, whereas in the latter case investment yields a loss. However, the signals may not provide perfect information. With an exogenously given fixed probability the signal gives the correct information. For simplicity, it is assumed that the signals can be observed without costs. They can be thought of for example as arising from media or publicly available marketing research. As an example of the duopoly model with signals, consider two soccer scouts who are considering to contract a player. In order to obtain information on the player's quality both scouts go to matches in which the wanted player plays. If he performs well, this can be seen as a signal indicating high revenues, but if he performs poorly, this is a signal that the investment is not profitable. This induces an option value of waiting for more signals to arrive and hence getting a better approximation of the actual profitability of the project.

On the side of the economic fundamentals underlying the model it is assumed that there are both a first mover and a second mover advantage. The first mover effect results from a Stackelberg advantage obtained by the first investor. The second mover advantage arises, because after one of the firms has invested, the true state of the project becomes known to both firms. The firm that has not invested yet benefits form this in that it can take its investment decision under complete information. In this paper it is shown that, depending on the prior beliefs on the profitability of the project and the magnitudes of the first and second mover advantages, either a preemption game or a war of attrition arises. The latter occurs if the information spillover exceeds the first mover Stackelberg effect. In the reverse case a preemption game arises. Even both types of games may occur in the same scenario: in a war of attrition there exists a positive probability that no firm undertakes the investment. Then it may happen - if enough good signals arrive - that at a certain point in time the first mover outweighs the information spillover, implying that a 
preemption game arises. It is shown that at the preemption point two things can happen in equilibrium. Firstly, one firm can invest while the other firm first waits to get the information spillover before it decides whether to invest or not. In this case the resulting market structure is a Stackelberg one. Secondly, both firms can invest simultaneously, thus resulting in e.g. a Cournot market. in that case both firms prefer a symmetrical situation in the output market above accepting the information spillover together with the Stackelberg disadvantage that is obtained upon investment by the competitor.

In this paper we show that the presence of information streams and uncertainty concerning the profitability of a new market leads to hybrid welfare results. We investigate the impact of information on expected ex ante welfare. For the monopoly case we find that welfare may in fact be decreasing in the quantity and quality of the signals. This is mainly due to the fact that when signals appear more frequently over time, or provide more reliable information, the option value of waiting for more information increases, which leads to investment at a later date, lowering consumer surplus. This result may extend to the duopoly case. One would expect that competitive pressure together with better information leads to earlier investment and thus to higher expected consumer surplus. There is, however, an opposite effect closely linked to the market structure. In equilibrium there is a certain probability that the actual outcome is a Stackelberg equilibrium. If this is the case and the market turns out to be bad there is only one firm that looses the sunk investment costs (namely the leader), while the follower will not invest at all. There is also a probability that the market ends up in a Cournot equilibrium with simultaneous investment at the preemption point. If the market turns out to be bad in this case there are two firms that loose the sunk investment costs. When more information is available, the information spillover is less valuable. This implies that a Cournot market will arise with a higher probability when the quality of information rises. In that case the resulting downward pressure on expected producer surplus (losing twice the sunk investment costs instead of once) might outweigh the increase in expected consumer surplus.

Secondly, simulations indicate that for low levels of quantity and quality of the signals a duopoly yields significantly higher levels of expected welfare. The intuition behind this result is straightforward. When the information stream is poor in both quantity and quality, the option value of waiting for a monopolist is low. Since for competing firms this value is already low due to competition, the standard deadweight loss argument applies here. We also find, however, that with high levels of quantity and quality of the signals, monopoly leads to significantly higher welfare levels than a duopoly. This is because of two reasons. Firstly, duopoly stimulates 
preemption which is bad for welfare because a significant value of waiting exists in case the expected information gain per unit of time is large. Secondly, the possibility of simultaneous investment in a preemptive duopoly has a negative effect on expected producer surplus, because there exists a possibility that the project turns out to be bad. These effects are larger than the increase in expected consumer surplus.

Most of the literature on optimal investment deals with the effects of either uncertainty or competition. The real option theory concerns itself with investment decisions under uncertainty (cf. Dixit and Pindyck (1996)). In this literature nature chooses a state of the world at each point in time, influencing the profitability of the investment project. The problem is then to find an optimal threshold level of an underlying variable (e.g. price or output value of the firm), above which the investment should be undertaken. A recent contribution in this area dealing with technology adoption is Alvarez and Stenbacka (2001) who include the opportunity to update the technology with future superior versions.

In the strategic interaction literature a number of models have been developed, dealing with different situations such as patent races and technology adoption. In general, a distinction can be made between two types of models. Firstly, there are preemption games in which two firms try to preempt each other in investing (cf. Fudenberg and Tirole (1991)). The equilibrium concept used in such games is developed in Fudenberg and Tirole (1985). Another class is the war of attrition, which is first introduced by Maynard Smith (1974) in the biological literature and later adopted for economic situations (cf. Tirole (1988)). Originally, the war of attrition describes two animals fighting over a prey. In an economic context one can think of two firms considering adopting a new technology. Both know that for one firm it would be optimal to invest, but neither wants to be the first to invest, since waiting for an even newer technology would be better. The equilibrium concept used in this type of game is introduced in Hendricks et al. (1988).

The literature combining both aspects is small indeed, see Grenadier (2000) for a survey. A first attempt to combine real option theory with timing games was made in Smets (1991). Huisman (2001) provides some extensions to this approach and applies this framework to technology adoption problems. Recent contributions include, e.g., Boyer et al. (2001) and Weeds (2002).

This paper extends the strategic real options literature in the direction of imperfect information. Jensen (1982) was the first to introduce uncertainty and imperfect information in a one-firm-model dealing with technology adoption. The present paper uses an information structure that is similar and which is discussed extensively in Thijssen et al. (2003) for the one firm case. In Mamer and McCardle (1987) the impact on the timing of innovation of costs, speed and quality of information 
arriving over time is studied for a one-firm model as well as a duopoly. However, due to an elaborate information structure, Mamer and McCardle (1987) did not obtain explicit results. Hoppe (2000) considers a duopoly framework in which it is a priori uncertain whether an investment project is profitable or not. The probability with which the project is profitable is exogenously given, fixed and common knowledge. As soon as one firm invests, the true profitability of the project becomes known. This creates informational spillovers that yield a second mover advantage.

The observation that a game of technology adoption under uncertainty is either a preemption game or a war of attrition dates back to Jensen (1992a). However, where Jensen (1992a) examines a two-stage adoption game, the present paper provides an extension of these results to the case of an infinite horizon continuous time framework. Moreover, as has been mentioned before, in our framework both types of games can occur within the same scenario. The equilibrium concept that we use is discussed in detail in Thijssen et al. (2002).

The present paper is related to Décamps and Mariotti (2000) who also consider a duopoly model where signals arrive over time. Differences are that in Décamps and Mariotti (2000) only bad signals exist and that signals are perfectly informative. This means that after receiving one signal the game is over since the firms are sure that the project is not profitable, while in our framework it could still be possible that the project is good. In Décamps and Mariotti it holds that, as long as no signal arrives, the probability that the project is good continuously increases over time and the firms are assumed to be asymmetric, which also induces uncertainty regarding the players' types, whereas we consider identical firms. Furthermore, Décamps and Mariotti apply the Bayesian equilibrium concept, whereas in our model this is not the case. Another implication is that a coordination problem between the two firms that occurs in our framework is not present in Décamps and Mariotti (2000). This coordination problem concerns the issue of which firm will be the first to invest in the preemption equilibrium. Another duopoly paper where information arrives over time is Lambrecht and Perraudin (2003). There, the information relates to the behaviour of the competitor: each firm has a certain belief about when the other firm will invest and this belief is updated by observing the other firm's behaviour.

The paper is organised as follows. In Section 2 the model is described. Then, in Section 3 we analyse the model for the scenario that the firm roles, i.e. leader and follower, are exogenously determined. In Section 4 the exogenous firm roles are dropped and the model is analysed for the case where the firms are completely symmetric. In Section 5 a welfare measure is introduced and welfare effects are discussed. Finally, Section 6 concludes the paper. 


\section{The Model}

We consider a situation in which two identical firms have the opportunity to invest in a project with uncertain revenues. Time is continuous and indexed by $t \in[0, \infty)$. The project can either be good (denoted by $H$ ), leading to high revenues, or bad (denoted by $L$ ), leading to low revenues. From the point of view of strategic behaviour there ar two possibilities. Let $\tau \geq 0$ denote the first point in time where investment takes place. If there is exactly one firm investing at time $\tau$ this firm is called the leader. The other firm then automatically becomes the follower. In our model this pattern of investment leads to Stackelberg competition. A second possibility is that both firms invest at time $\tau$, leading to Cournot-Nash competition.

After investment has taken place by at least one firm it is assumed that the state of the project becomes immediately known to both firms. Hence, in the case where there is a leader and a follower there is an information spillover from the leader to the follower, which creates a second mover advantage. In that case, the follower decides on investment immediately after the true state of the project is revealed. It is assumed that this does not take any time. So, if one firm invests at time $\tau \geq 0$, the follower will either invest at time $\tau$ as well or not at all. We distinguish this case from the case of simultaneous investment where both firms also invest at the same time $\tau \geq 0$, but without one of the firms having the second mover advantage. ${ }^{1}$ That is, in case of simultaneous investment, at the time of investment both firms are uncertain as to the true state of the project.

In case the project is good the leader's revenue equals $U_{L}^{H}>0$, whereas if the project is bad the leader's revenue equals $U_{L}^{L}=0$. The sunk costs of investment are given by $I>0$. If the project is good, the follower will immediately invest as well and gets revenue $U_{F}^{H}>0$. The follower will also incur the sunk costs $I$. It is assumed that $U_{L}^{H}>U_{F}^{H}>I$. Hence, there is a first mover advantage if the project turns out to yield a high revenue and investment is profitable for both firms. If the project is bad the payoff for the follower equals $U_{F}^{L}=U_{L}^{L}=0$. So, if the project is bad the follower observes this due to the information spillover and thus refrains from investment. This implies that in case of a bad project, only the leader incurs a loss that is equal to the sunk costs of investment. To see who is in the best position, the leader or the follower, the magnitudes of the first and second mover advantages

\footnotetext{
${ }^{1}$ The assumption that the follower reacts immediately might seem unrealistic, but is not very restrictive. If for example there is a time lag between investment of the leader and the follower this only has an influence on the payoffs via extra discounting by the follower. The important point is that the game ends as soon as one firm has invested, because then the decision of the other firm is made as well. The fact that actual investment may take place at a later date is irrelevant for the qualitative analysis.
} 
have to be compared.

If both firms invest simultaneously and the project turns out to be good, both receive $U_{M}^{H}>0$, where $U_{F}^{H}<U_{M}^{H}<U_{L}^{H}$. The revenues can be seen as an infinite stream of payoffs $\pi_{j}^{i}$ discounted at rate $r \in(0,1)$, i.e. $U_{j}^{i}=\int_{0}^{\infty} e^{-r t} \pi_{j}^{i} d t=\frac{1}{r} \pi_{j}^{i}$, $i=H, L, j=L, M, F$. Example 1 illustrates this framework.

Example 1 Consider a new market for a homogeneous good. Two firms have the opportunity to enter the market, that can be either good or bad. Let market demand be given by $P(Q)=Y-Q$ for some $Y>0$ if the market is good $(H)$ and by $P(Q)=0$ if the market is bad $(L)$. The cost function is given by $C(q)=c q$, for some $0 \leq c \leq Y$. It is assumed that if the firms invest they engage in quantity competition. If the market turns out to be bad, then the action to take is not to produce, i.e. $U_{L}^{L}=U_{F}^{L}=U_{M}^{L}=0$. Suppose that there is one firm that invests in the market first. This firm then is the Stackelberg leader. ${ }^{2}$ In case the market is good the follower solves the following profit maximisation problem:

$$
\max _{q_{F} \geq 0} \frac{1}{r} q_{F}\left[P\left(q_{L}+q_{F}\right)-c\right]
$$

where $r$ is the discount rate. This yields $q_{F}=\frac{Y-c-q_{L}}{2}$. Using this reaction, the leader maximises its stream of profits. Solving the corresponding maximisation problem yields $q_{L}=\frac{Y-c}{2}$, which results in $q_{F}=\frac{Y-c}{4}$, and the payoffs $U_{L}^{H}=\frac{(Y-c)^{2}}{8 r}$ and $U_{F}^{H}=\frac{(Y-c)^{2}}{16 r}$, respectively. In case both firms invest simultaneously, the CournotNash outcome prevails. Straightforward computations yield $U_{M}^{H}=\frac{(Y-c)^{2}}{9 r}$. Note that $U_{L}^{H}>U_{M}^{H}>U_{F}^{H} \cdot^{3}$

It is assumed that both firms have an identical belief $p \in[0,1]$ in the project being good. This belief is assumed to be common knowledge. If the leader invests at a point in time where the belief in a good project equals $p$, the leader's ex ante expected payoff equals

$$
L(p)=p\left(U_{L}^{H}-I\right)+(1-p)(-I)=p U_{L}^{H}-I .
$$

The follower only invests in case of a good project. Therefore, if the leader invests when the belief in a good project equals $p$, the ex ante expected payoff for the follower equals

$$
F(p)=p\left(U_{F}^{H}-I\right) .
$$

\footnotetext{
${ }^{2}$ It is assumed that firms can only set capacity once, thereby fixing the production level forever. This resolves the commitment problem mentioned in Dixit (1980).

${ }^{3}$ The assumption of an infinite Stackelberg advantage may seem to be highly restrictive and unrealistic. For our framework, however, this assumption is not essential. The main point is that it should be the case that the first mover has a higher discounted present value if the market is good. This could also be established by a temporary Stackelberg advantage.
} 
In case of simultaneous investment at belief $p$, each firm has an ex ante expected payoff that equals

$$
M(p)=p U_{M}^{H}-I .
$$

Define by $p_{M}$ the belief such that the ex ante expected profit for the follower equals the ex ante expected profit of simultaneous investment, i.e. $p_{M}$ is such that $F\left(p_{M}\right)=$ $M\left(p_{M}\right)$. Note that, when $p \geq p_{M}$, both firms will always invest simultaneously, i.e. before the true state of the project is known, yielding payoffs

$$
l(p)= \begin{cases}L(p) & \text { if } p<p_{M} \\ M(p) & \text { if } p \geq p_{M}\end{cases}
$$

for the leader and

$$
f(p)= \begin{cases}F(p) & \text { if } p<p_{M} \\ M(p) & \text { if } p \geq p_{M}\end{cases}
$$

for the follower. A graphical representation of these payoffs is given in Figure 1.

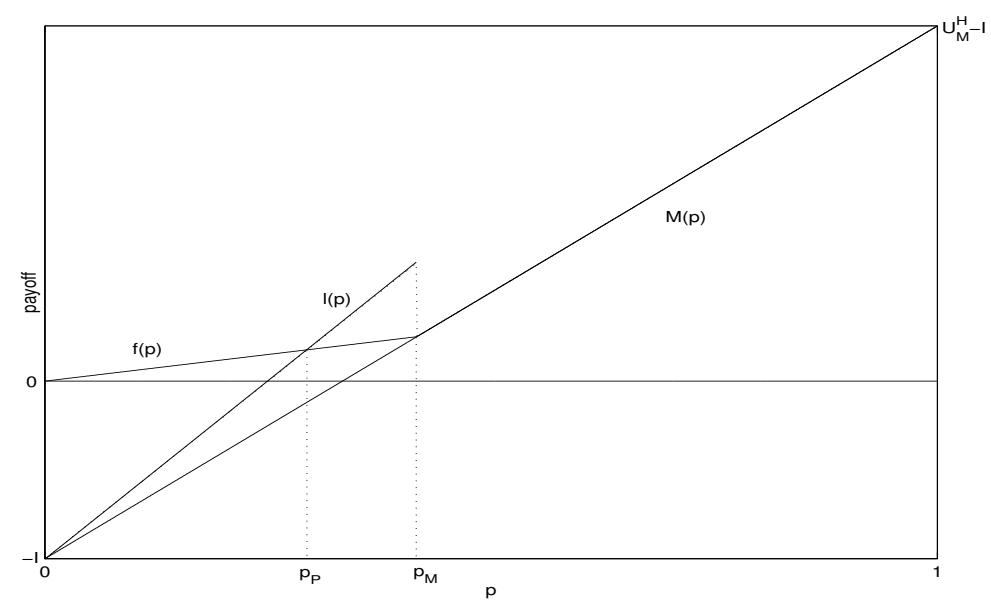

Figure 1: Payoff functions.

At the moment that the investment opportunity becomes available, both firms have an identical prior belief about the project yielding high revenues, say $p_{0} \in(0,1)$, which is common knowledge. Occasionally, the firms obtain information in the form of signals about the profitability of the project. These signals are observed by both firms simultaneously and are assumed to arrive according to a Poisson process with parameter $\mu>0$. Information arriving over time will in general be heterogeneous regarding the indication of the profitability level of the project. We distinguish two types of signals: a signal can either indicate high revenues (an $h$-signal) or low 
revenues (an $l$-signal). A signal revealing the true state of the project occurs with the common knowledge probability $\lambda>\frac{1}{2}$, see Table $1 .{ }^{4}$

\begin{tabular}{c|c|c} 
& $h$ & $l$ \\
\hline$H$ & $\lambda$ & $1-\lambda$ \\
\hline$L$ & $1-\lambda$ & $\lambda$
\end{tabular}

Table 1: Conditional probabilities of $h$ - and $l$-signals.

Let $n$ denote the number of signals and let $g$ and $b$ be the number of $h$-signals and $l$-signals, respectively, so that $n=g+b$. Given that at a certain point in time $n$ signals have arrived, $g$ of which were $h$-signals, the firms then calculate their belief in a good project in a Bayesian way. Define $k=2 g-n=g-b$ so that $k>0(k<0)$ indicates that more (less) $h$-signals than $l$-signals have arrived. After defining the prior odds of a bad project as $\zeta=\frac{1-p_{0}}{p_{0}}$, it is obtained from Thijssen et al. (2003) that the (conditional) belief in a good project is a function of $k$ and is given by

$$
p(k)=\frac{\lambda^{k}}{\lambda^{k}+\zeta(1-\lambda)^{k}} .
$$

Note that the inverse of this function gives the number of $h$-signals in excess of $l$-signals that is needed to obtain a belief equal to $p$ :

$$
k(p)=\frac{\log \left(\frac{p}{1-p}\right)+\log (\zeta)}{\log \left(\frac{\lambda}{1-\lambda}\right)} .
$$

\section{Exogenous Firm Roles}

Before we turn to the case where it is endogenously determined which firm invests first, we now look at the simpler case of exogenous firm roles. There are two symmetric cases, namely one being that only firm 1 is allowed to be the first investor and the other being its symmetric counterpart. Suppose that only firm 1 is allowed to be the first investor. Then firm 1 does not need to take into account the possibility that firm 2 preempts. Firm 2 can choose between the follower role, i.e. waiting to incur the second mover advantage, and investing at the same time as firm 1, i.e. without waiting for the true state of the project to become known. These two cases lead to different forms of competition if the project turns out to be profitable. In the first case a Stackelberg equilibrium arises, whereas in the latter case a Cournot

\footnotetext{
${ }^{4}$ Without loss of generality it can be assumed that $\lambda>\frac{1}{2}$, since if the converse holds we can redefine the $h$-signals to be $l$-signals and vice versa. Then a signal again reveals the true state of the project with probability $1-\lambda>\frac{1}{2}$. If $\lambda=\frac{1}{2}$ the signal is uninformative and, consequently, the value of waiting disappears.
} 
equilibrium is to be expected. Firm 1 should invest at the point in time at which its belief in a good project exceeds a certain threshold. In case of the Stackelberg equilibrium it holds that, analogous to Thijssen et al. (2003), that this threshold belief, denoted by $p_{L}$, is given by

$$
p_{L}=\frac{1}{\Psi\left(U_{L}^{H} / I-1\right)+1},
$$

where

$$
\Psi=\frac{\beta(r+\mu)(r+\mu(1-\lambda))-\mu \lambda(1-\lambda)(r+\mu(1+\beta-\lambda))}{\beta(r+\mu)(r+\mu \lambda)-\mu \lambda(1-\lambda)(r+\mu(\beta+\lambda))}
$$

and

$$
\beta=\frac{r+\mu}{2 \mu}+\frac{1}{2} \sqrt{\left(\frac{r}{\mu}+1\right)^{2}-4 \lambda(1-\lambda)} .
$$

Hence, as soon as $p$ exceeds $p_{L}$, the leader invests. Then, the follower immediately decides whether or not to invest, based on the true state of the project that is immediately revealed after the investment by the leader. Note that $p_{L}$ will not be hit exactly, since the belief $p(k)$ jumps alongside with the discrete variable $k$. Hence, the leader invests when $p=p\left(\left\lceil k_{L}\right\rceil\right)$, where $k_{L}=k\left(p_{L}\right)$.

The above story only holds if $p\left(\left\lceil k_{L}\right\rceil\right)<p_{M}$. If the converse holds, firm 1 knows that firm 2 will not choose the follower role, but will invest immediately as well yielding $U_{M}^{H}$ instead of $U_{L}^{H}$ if the project turns out to be good. Then a Cournot equilibrium arises and the threshold in this case is equal to

$$
\tilde{p}_{L}=\frac{1}{\Psi\left(U_{M}^{H} / I-1\right)+1} .
$$

Note that since $U_{L}^{H}>U_{M}^{H}$ it holds that $\tilde{p}_{L}>p_{L}$.

When $p_{0}$ is contained in the region $\left(p_{M}, 1\right]$, both firms will immediately invest, yielding for both a discounted payoff stream $U_{M}^{H}-I$ if the project is good, and $-I$ if the project is bad. Like in the Cournot equilibrium, here too the belief is such that the follower prefers to receive the simultaneous investment payoff rather than being a follower, implying that it takes the risk of making a loss that equals the sunk costs of investment when the project value is low.

\section{Endogenous Firm Roles}

Let the firm roles now be endogenous, which implies that both firms can be the first investor. Define the preemption belief, denoted by $p_{P}$, to be the belief at which the leader value equals the follower value, i.e. where $L\left(p_{P}\right)=F\left(p_{P}\right)$ (cf. Figure 1). This gives

$$
p_{P}=\frac{I}{U_{L}^{H}-U_{F}^{H}+I}
$$


Note that $p_{P}<p_{M}$. As soon as $p$ reaches $p_{P}$ (if ever), both firms want to be the leader and try to preempt each other, which erodes the option value of waiting. It does not vanish completely, however, since $L\left(p_{P}\right)>0$. This indicates that the net present value of the investment of the preemptor is still positive. Furthermore, define $k_{P}=k\left(p_{P}\right)$. For the analysis an important part is played by the positioning of $k_{L}$, which can be smaller or larger than $k_{P}$. Since $k$ is monotonically increasing in $p$, from (3) and (4) it follows that

$$
k_{L}>k_{P} \Longleftrightarrow \Psi<\frac{U_{L}^{H}-U_{F}^{H}}{U_{L}^{H}-I} .
$$

Note that if $k_{L}>k_{P}$ then $\left\lceil k_{L}\right\rceil \geq\left\lceil k_{P}\right\rceil$. The right-hand side of the second inequality in (5) can be seen as the relative price that the follower pays for waiting to obtain the information spillover. Since $\Psi$ decreases with $\lambda$ and (in general) with $\mu$ (see Thijssen et al. (2003)), $\Psi$ increases with the value of the information spillover. For if $\Psi$ is low, the quality and the quantity of the signals are relatively high. Therefore, if a firm becomes the leader it provides relatively less information to its competitor for low values of $\Psi$ compared to when $\Psi$ is high. So, expression (5) implies a comparison between the first mover advantage and the second mover advantage. In what follows we consider the two cases $\left\lceil k_{L}\right\rceil \geq\left\lceil k_{P}\right\rceil$ and $\left\lceil k_{L}\right\rceil<\left\lceil k_{P}\right\rceil$.

\subsection{The Case Where the Leader Advantage Outweighs the Infor- mation Spillover}

Suppose that $\left\lceil k_{L}\right\rceil \geq\left\lceil k_{P}\right\rceil$. In this case firms start to duel over the leader role as soon as $k=\left\lceil k_{P}\right\rceil$, whereas an exogenously assigned leader would wait until $k=\left\lceil k_{L}\right\rceil$. This implies that firms try to preempt each other in investing in the project. We apply the equilibrium concept introduced in Fudenberg and Tirole (1985), which is extended for the present setting involving uncertainty in Thijssen et al. (2002), to solve the game. In Appendix A a brief review of the appropriate strategy and equilibrium concepts can be found. The application of this equilibrium concept requires the use of several stopping times. Define for all starting points $t_{0} \geq 0$, $T_{P}^{t_{0}}=\inf \left\{t \geq t_{0} \mid p_{t} \geq p_{P}\right\}$ and $T_{M}^{t_{0}}=\inf \left\{t \geq t_{0} \mid p_{t} \geq p_{M}\right\}$, where $p_{t} \equiv p\left(k_{t}\right)$ and $k_{t}$ is the number of $h$-signals in excess of $l$-signals at time $t$. Note that $T_{M}^{t_{0}} \geq T_{P}^{t_{0}}$ a.s. for all $t_{0} \geq 0$. In what follows we consider three different starting points, namely $p_{t_{0}} \geq p_{M}, p_{P} \leq p_{t_{0}}<p_{M}$ and $p_{t_{0}}<p_{P}$.

If $p_{t_{0}} \geq p_{M}$ the value of simultaneous investment is greater than or equal to the value of being the second investor. If the inequality is strict this implies that no firm wants to be the follower and hence that both firms will invest immediately. If $p_{t_{0}}=$ 
$p_{M}$ firms are indifferent between being the follower and simultaneous investment. ${ }^{5}$

Next, let $p_{P} \leq p_{t_{0}}<p_{M}$ be the starting point of the game. Both firms try to preempt in this scenario, since the value for the leader is higher than the value for the follower. This implies that in a symmetric equilibrium ${ }^{6}$ each firm invests with a positive probability. Here both firms want to be the first investor, since the expected Stackelberg leader payoff is sufficiently high. Equivalently, the belief in a good project is sufficiently high for taking the risk that the project has a low payoff to be optimal. On the other hand, if the firms invest with positive probability, the probability that both firms simultaneously invest is also positive. This would lead to the simultaneous investment (Cournot-Nash) payoff. However, since $t_{0}<T_{M}^{t_{0}}$ this payoff is not high enough for simultaneous investment as such to be optimal. We conclude that there is a trade-off here between getting the high payoff as a leader or a low payoff that is influenced by the risk of investing in a bad project as a leader, the lower payoff of being the follower, and the lower payoff of (a suboptimal) simultaneous investment. As is proved in Proposition 1 below, the probability that a firm invests equals $\frac{L(p)-M(p)}{L(p)-2 M(p)+F(p)}$. Hence, this probability decreases with the difference between the leader and the simultaneous investment payoff. This happens because if this difference is large the firms will try to avoid simultaneous investment by lowering their investment probability.

From Thijssen et al. (2002) it is known that it is optimal if one of the two firms invests as soon as the preemption region is reached. The equilibrium strategies are such that the probability that at least one firm invests equals one. ${ }^{7}$ Since immediately after investment by the leader the follower decides on investment, the game ends exactly at the point in time where the preemption region is reached. Again, the position of $p_{L}$ is of no importance, since the leader curve lies above the follower curve, implying that both firms will try to become the leader.

The last region is the region where $p_{t_{0}}<p_{P}$. As long as $t_{0} \leq t<T_{P}^{t_{0}}$, the leader curve lies under the follower curve, and since in this case $k_{L} \geq k_{P}, p_{L}$ has not been

\footnotetext{
${ }^{5}$ Note that whether or not $p_{M}>p_{L}$ is irrelevant. For suppose that $p_{M} \leq p_{L}$. Then no firm would be willing to wait until $p_{L}$ is reached, because of the sheer fear of being preempted by the other firm.

${ }^{6}$ Since the firms are identical, a symmetric equilibrium seems to be the most plausible candidate. See Thijssen et al. (2002) for a more elaborate discussion of this point.

${ }^{7}$ Note that the probability of simultaneous investment at $T_{P}^{t_{0}}$ is strictly positive, even if $t_{0}<T_{P}^{t_{0}}$. This happens because the preemption point will not be hit exactly due to the discontinuity of the stochastic process governing the evolution of $p$. In the standard game theoretic real options literature (e.g. Weeds (2002)) one uses a less complicated equilibrium concept and simply assumes that the probability of simultaneous investment at the preemption point equals zero. Such an assumption would be unjustified here.
} 
reached yet. Hence, no firm wants to be the leader and both firms abstain from investment until enough $h$-signals have arrived to make investment more attractive than waiting.

Formally, the above discussion can be summarised in a consistent $\alpha$-equilibrium. This equilibrium concept for game theoretic real options models is described in detail in Thijssen et al. (2002). The strategies used in these timing games consist of a cumulative distribution function $G^{t_{0}}(\cdot)$, where $G_{i}^{t_{0}}(t)$ gives the probability that firm $i$ has invested before and including time $t \geq t_{0}$, and an intensity function $\alpha^{t_{0}}(\cdot)$. The intensity function serves as an endogenous coordination device in cases where it is optimal for one firm to invest but not for both. In coordinating firms make a trade-off between succeeding in investing first and the risk of both investing at the same time. For details, see Appendix A.

Proposition 1 If $\Psi \leq \frac{U_{L}^{H}-U_{F}^{H}}{U_{L}^{H}-I}$, then a symmetric consistent $\alpha$-equilibrium is given by the tuple of closed-loop strategies $\left(\left(G_{1}^{t}, \alpha_{1}^{t}\right),\left(G_{2}^{t}, \alpha_{2}^{t}\right)\right)_{t \in[0, \infty)}$, where for $i=1,2$

$$
\begin{aligned}
G_{i}^{t}(s) & = \begin{cases}0 & \text { if } s<T_{P}^{t}, \\
\frac{L\left(p_{T_{P}^{t}}\right)-M\left(p_{T_{P}^{t}}\right)}{L\left(p_{T_{P}^{t}}\right)-2 M\left(p_{T_{P}^{t}}\right)+F\left(p_{T_{P}^{t}}\right)} & \text { if } T_{P}^{t} \leq s<T_{M}^{t}, \\
1 & \text { if } s \geq T_{M}^{t},\end{cases} \\
\alpha_{i}^{t}(s) & = \begin{cases}0 & \text { if } s<T_{P}^{t}, \\
\frac{L\left(p_{T_{P}^{t}}\right)-F\left(p_{T_{P}^{t}}\right)}{L\left(p_{T_{P}^{t}}\right)-M\left(p_{T_{P}^{t}}\right)} & \text { if } T_{P}^{t} \leq s<T_{M}^{t}, \\
1 & \text { if } s \geq T_{M}^{t} .\end{cases}
\end{aligned}
$$

For a proof of this proposition, see Appendix B.

\subsection{The Case Where the Information Spillover Outweighs the Leader Effect}

Suppose that $p_{L}<p_{P}$. Now the problem becomes somewhat different. Let $t_{0} \geq 0$. For $t>T_{P}^{t_{0}}$ the game is exactly the same as in the former case. The difference arises if $t \geq t_{0}$ is such that $p_{t} \in\left[p_{L}, p_{P}\right)$. In this region it would have been optimal to invest for the leader in case the leader role had been determined exogenously. However, since the leader role is endogenous and the leader curve lies below the follower curve, both firms prefer to be the follower. In other words, a war of attrition (cf. Hendricks et al. (1988)) arises. Two asymmetric equilibria of the war of attrition arise trivially: firm 1 invests always with probability one and firm 2 always with probability zero, 
and vice versa. However, since the firms are assumed to be identical there is no $a$ priori reason to expect that they coordinate on one of these asymmetric equilibria.

We know that the game ends as soon as $T_{P}^{t_{0}}$ is reached. Note, however, that before this happens $p_{L}$ can be reached several times, depending on the arrival of $h$ - and $l$-signals. There is a war of attrition for $k \in K=\left\{\left\lceil k_{L}\right\rceil, \ldots,\left\lceil k_{P}\right\rceil-1\right\}$. To keep track of the points in time where a war of attrition occurs, define the following increasing sequence of stopping times: $T_{1}^{t_{0}}=\inf \left\{t \geq t_{0} \mid p_{t}=\left\lceil p_{L}\right\rceil\right\}, T_{n+1}^{t_{0}}=\inf \{t>$ $\left.T_{n}^{t_{0}} \mid \exists_{k \in K}: p_{t}=p(k)\right\}, n=1,2,3, \ldots$, with the corresponding levels of $h$-signals in excess of $l$-signals $k_{n}=k\left(p_{T_{n}^{t_{0}}}\right)$. Note that $n$ is the number of signals that have arrived up until and including time $T_{n}^{t_{0}}$ since the first time the war of attrition region has been reached.

To find a symmetric equilibrium we argue in line with Fudenberg and Tirole (1991) that for each point in time during a war of attrition the expected revenue of investing directly exactly equals the value of waiting a small period of time $d t$ and investing when a new signal arrives. ${ }^{8}$ The expected value of investing at each point in time depends on the value of $k$ at that point in time. Let $k_{t} \in K$ for some $t \geq t_{0}$. Denoting the probability that the other firm invests at belief $p\left(k_{t}\right)$ by $\gamma\left(k_{t}\right)$, the expected value of investing at time $t$ equals

$$
V_{1}\left(p_{t}\right)=\gamma\left(k_{t}\right) M\left(p_{t}\right)+\left(1-\gamma\left(k_{t}\right)\right) L\left(p_{t}\right) .
$$

The value of waiting for an infinitesimal small amount of time equals the weighted value of becoming the follower and of both firms waiting, i.e.

$$
V_{2}\left(p_{t}\right)=\gamma\left(k_{t}\right) F\left(p_{t}\right)+\left(1-\gamma\left(k_{t}\right)\right) \tilde{V}\left(p_{t}\right),
$$

where $\tilde{V}(p)$ is the value of waiting when neither firm invests. Let $\gamma(\cdot)$ be such that $V_{1}(\cdot)=V_{2}(\cdot)$.

To actually calculate $\gamma(k)$ for all $k \in K$, we use the fact that only for certain values of $p$ the probability of investment needs to be calculated. These probabilities are the beliefs that result from the signals, i.e. for the beliefs $p$ such that $p=p(k)$, $k \in K$. For notational convenience we take $k$ as dependent variable instead of $p$. For example, we write $V(k)$ instead of $V(p(k))$. To calculate the isolated atoms the probabilities of investment - in the war of attrition, $\gamma(\cdot)$, the value of waiting $\tilde{V}(\cdot)$ needs to be determined. It is governed by the following equation:

$$
\begin{aligned}
\tilde{V}(k)= & e^{-r d t}\left\{(1-\mu d t) \tilde{V}(k)+\mu d t\left[p(k)\left(\lambda V_{1}(k+1)+(1-\lambda) V_{1}(k-1)\right)+\right.\right. \\
& \left.\left.+(1-p(k))\left(\lambda V_{1}(k-1)+(1-\lambda) V_{1}(k+1)\right)\right]\right\} .
\end{aligned}
$$

\footnotetext{
${ }^{8}$ It might seem strange that a firm then also invests when a bad signal arrives. Note, however, that it is always optimal for one firm to invest in the war of attrition region. The probability of investment is most likely lower for lower values of $p$.
} 
Eq. (10) arises from equalizing the value of $\tilde{V}(k)$ to the value an infinitesimally small amount of time later. In this small time interval, nothing happens with probability $1-\mu d t$. With probability $\mu d t$ a signal arrives. The belief a firm has in a good project is given by $p(k)$. If the project is indeed good, an $h$-signal arrives with probability $\lambda$, and an $l$-signal arrives with probability $1-\lambda$. Vice versa if the project is bad. If a signal arrives then investing yields either $V_{1}(k+1)$ or $V_{1}(k-1)$. After letting $d t \downarrow 0$ and substituting eqs. (1) and (8) into eq. (10) it is obtained that

$$
\begin{aligned}
\tilde{V}(k)= & \frac{\mu}{r+\mu}\left[\frac{\lambda^{k+1}+\zeta(1-\lambda)^{k+1}}{\lambda^{k}+\zeta(1-\lambda)^{k}}(\gamma(k+1) M(k+1)+(1-\gamma(k+1))\right. \\
& L(k+1))+\lambda(1-\lambda) \frac{\lambda^{k-1}+\zeta(1-\lambda)^{k-1}}{\lambda^{k}+\zeta(1-\lambda)^{k}}(\gamma(k-1) M(k-1) \\
& +(1-\gamma(k-1)) L(k-1))] .
\end{aligned}
$$

Substituting eq. (11) into eq. (9) yields, after equating eqs. (9) and (8) and rearranging:

$$
a_{k} \gamma(k)+b_{k}=(1-\gamma(k))\left(c_{k} \gamma(k+1)+d_{k} \gamma(k-1)+e_{k}\right),
$$

where

$$
\begin{aligned}
a_{k}= & M(k)-L(k)-F(k), \\
b_{k}= & L(k), \\
c_{k}= & \frac{\mu}{r+\mu} \frac{\lambda^{k+1}+\zeta(1-\lambda)^{k+1}}{\lambda^{k}+\zeta(1-\lambda)^{k}}(M(k+1)-L(k+1)), \\
d_{k}= & \frac{\mu}{r+\mu} \lambda(1-\lambda) \frac{\lambda^{k-1}+\zeta(1-\lambda)^{k-1}}{\lambda^{k}+\zeta(1-\lambda)^{k}}(M(k-1)-L(k-1)), \\
e_{k}= & \frac{\mu}{r+\mu}\left(\frac{\lambda^{k+1}+\zeta(1-\lambda)^{k+1}}{\lambda^{k}+\zeta(1-\lambda)^{k}} L(k+1)\right. \\
& \left.+\lambda(1-\lambda) \frac{\lambda^{k-1}+\zeta(1-\lambda)^{k-1}}{\lambda^{k}+\zeta(1-\lambda)^{k}} L(k-1)\right) .
\end{aligned}
$$

To solve for $\gamma(\cdot)$ note that if $k<\left\lceil k_{L}\right\rceil$, no firm will invest, since the option value of waiting is higher than the expected revenues of investing. Therefore $\gamma\left(\left\lceil k_{L}\right\rceil\right)=0$. On the other hand, if $k \geq\left\lceil k_{P}\right\rceil$ the firms know that they enter a preemption game, i.e. $\gamma\left(\left\lceil k_{P}\right\rceil\right)=G_{i}^{t}\left(T_{P}^{t}\right)$, where $G_{i}^{t}\left(T_{P}^{t}\right)$ can be obtained from Proposition 1 . Note that it is possible that $\left\lceil k_{P}\right\rceil=\left\lceil k_{M}\right\rceil$. Then the game proceeds from the war of attrition directly into the region where simultaneous investment is optimal. This happens if $T_{M}^{t}=T_{P}^{t}$. In this case the expected payoff is governed by $M(\cdot)$. For other values of $k$, we have to solve a system of equations, where the $k$-th entry is given by eq. (12). The complete system can be written as

$$
\operatorname{diag}(\gamma) \mathbf{A} \gamma+\mathbf{B} \gamma=\mathbf{b}
$$


for appropriately chosen matrices $\mathbf{A}$ and $\mathbf{B}$, and vector $\mathbf{b}$. The system of equations (13) cannot be solved analytically. However, for any specific set of parameter values, a numerical solution can be determined. The following lemma shows that a solution always exists. The proof can be found in Appendix C.

Lemma 1 The system of equations (13) has a solution. Furthermore, $\gamma(k) \in[0,1]$ for all $k \in K$.

Define $n_{t}=\sup \left\{n \mid T_{n}^{t_{0}} \leq t\right\}$ to be the number of signals that has arrived up until time $t \geq t_{0}$. In the following proposition a symmetric consistent $\alpha$-equilibrium is given.

Proposition 2 If $\Psi>\frac{U_{L}^{H}-U_{F}^{H}}{U_{L}^{H}-I}$, then a consistent $\alpha$-equilibrium is given by the tuple of closed-loop strategies $\left(\left(G_{1}^{t}, \alpha_{1}^{t}\right),\left(G_{2}^{t}, \alpha_{2}^{t}\right)\right)_{t \in[0, \infty)}$, where for $i=1,2$

$$
\begin{aligned}
G_{i}^{t}(s) & = \begin{cases}0 & \text { if } s<T_{1}^{t} \\
\sum_{n=n_{t}}^{n_{s}} \frac{\gamma\left(k_{n}\right)}{1-\gamma\left(k_{n}\right)} \prod_{n^{\prime}=n_{t}}^{n}\left(1-\gamma\left(k_{n^{\prime}}\right)\right) & \text { if } T_{1}^{t} \leq s<T_{P}^{t}, \\
\left(1-G_{i}^{t}\left(T_{P}^{t}-\right)\right) \frac{L\left(p_{T_{P}^{t}}\right)-M\left(p_{T_{P}}\right)}{L\left(p_{T_{P}^{t}}\right)-2 M\left(p_{T_{P}^{t}}\right)+F\left(p_{T_{P}}\right)} & \text { if } T_{P}^{t} \leq s<T_{M}^{t}, \\
1 & \text { if } s \geq T_{M}^{t}, \text { or } s>T_{P}^{t} \text { and } H,\end{cases} \\
\alpha_{i}^{t}(s) & = \begin{cases}0 & \text { if } s<T_{P}^{t}, \\
\frac{L\left(p_{T_{P}^{t}}\right)-F\left(p_{T_{P}^{t}}\right)}{L\left(p_{T_{P}^{t}}\right)-M\left(p_{T_{P}^{t}}\right)} & \text { if } T_{P}^{t} \leq s<T_{M}^{t}, \\
1 & \text { if } s \geq T_{M}^{t} .\end{cases}
\end{aligned}
$$

The proof of Proposition 2 can be found in Appendix D.

An illustration of the case where the second mover advantage outweighs the first mover advantage can be found in the following example.

Example 2 Consider a situation whose characteristics are given in Table 2. For

\begin{tabular}{||l|r||}
\hline$U_{L}^{H}=13.3$ & $r=0.1$ \\
\hline$U_{F}^{H}=13$ & $\mu=2$ \\
\hline$U_{M}^{H}=13.2$ & $\lambda=0.7$ \\
\hline$I=2$ & $p_{0}=0.5$ \\
\hline
\end{tabular}

Table 2: Parameter values.

this example the preemption belief equals $p_{P}=0.87$. The minimal belief that an exogenous leader needs to invest optimally is given by $p_{L}=0.51$. Using eq. (2) this 
implies that a war of attrition arises for $k \in\{1,2\}$. Solving the system of equations given in (13) yields the vector of probabilities with which each firm invests in the project. It yields $\gamma(1)=0.4547$ and $\gamma(2)=0.7613$.

From this example one can see that the probability of investment increases rapidly and is substantial. Both firms know that, given that the project is good, it is better to become the leader. So, as the belief in a good project increases, both firms invest with higher probability.

\section{Welfare Analysis}

Welfare effects resulting from investment under uncertainty have been reported by e.g. Jensen (1992b) and Stenbacka and Tombak (1994). In both papers the timing of investment does not depend on the arrival of signals. In these papers the uncertainty comprises the time needed to successfully implement the investment, i.e. the time between investment and the successful implementation of the investment is stochastic. The models in Jensen (1992b) and Stenbacka and Tombak (1994) allow for the critical levels to be explicit points in time. In our model, the critical level is not measured in units of time but measured as a probability, i.e. a belief. To perform a welfare analysis, however, it is necessary to incorporate the time element in the model.

For simplicity we only consider preemption cases $\left(p_{0}<p_{P}<p_{L}\right)$. The resulting equilibrium implies that as soon as $\left\lceil k_{P}\right\rceil$ is reached, at least one firm invests and the game ends. We analyse two questions relating to welfare that, at first sight, are expected to have obvious answers. First, we investigate if more and/or better information leads to higher levels of expected ex ante welfare. Secondly, we analyse if competition (in duopoly) is better from a social welfare point of view than monopoly.

Given the belief in a good project $p \in\left[p_{P}, p_{M}\right)$, the probability of simultaneous investment, denoted by $b(p)$, is given by (cf. (7) and (17)):

$$
b(p)=\frac{L(p)-F(p)}{L(p)-2 M(p)+F(p)} .
$$

Let $C S_{M}^{l}$ denote the discounted value of consumer surplus if the project is $l \in\{L, H\}$ and simultaneous investment takes place. Furthermore, let $C S_{S}^{H}$ and $C S^{L}$ denote the infinite discounted stream of consumer surplus in the Stackelberg equilibrium if the project is good, and the infinite discounted stream of consumer surplus if the project is bad and one firm invests, respectively.

If the critical number of $h$-signals in excess of $l$-signals is given by $k \geq 0$ with first passage time $t$, the expected discounted total surplus if the project gives high 
revenues is given by

$$
\begin{aligned}
E S^{H}(k, t)= & e^{-r t}\left[b(p(k))\left(2 U_{M}^{H}+C S_{M}^{H}\right)\right. \\
& \left.+(1-b(p(k)))\left(U_{L}^{H}+U_{F}^{H}+C S_{S}^{H}\right)-2 I\right],
\end{aligned}
$$

whereas if the project gives a low revenue the expected total surplus equals

$$
E S^{L}(k, t)=e^{-r t}\left[b(p(k))\left(C S_{M}^{L}-2 I\right)+(1-b(p(k)))\left(C S^{L}-I\right)\right] .
$$

The expected total surplus with critical level $k$ and first passage time $t$ is then given by

$$
W(k, t)=p(k) E S^{H}(k, t)+(1-p(k)) E S^{L}(k, t) .
$$

To incorporate the uncertainty regarding the first passage time through $k$, we define the ex ante expected total welfare $W(k)$ to be the expectation of $W(k, t)$ over the first passage time through $k$. That is,

$$
\begin{aligned}
W(k) & =\mathbb{E}_{k}(W(k, t)) \\
& =\int_{0}^{\infty} W(k, t) f_{k}(t) d t,
\end{aligned}
$$

where $f_{k}(\cdot)$ is the probability density function (pdf) of the first passage time through $k$.

The pdf of the first passage time through $k \geq 0$ is given in the following proposition, the proof of which can be found in Appendix E.

Proposition 3 Let $k_{0}=0$ a.s. The probability density function $f_{k}(\cdot)$ of the first passage time through $k \geq 0$ is given by

$$
f_{k}(t)=\frac{\lambda^{k}+\zeta(1-\lambda)^{k}}{1+\zeta}(\lambda(1-\lambda))^{-k / 2} \frac{k}{t} I_{k}(2 \mu \sqrt{\lambda(1-\lambda)} t) e^{-\mu t},
$$

for all $t \geq 0$. Here,

$$
I_{\rho}(x)=\sum_{l=0}^{\infty} \frac{1}{l ! \Gamma(l+\rho+1)}\left(\frac{x}{2}\right)^{2 l+\rho},
$$

is the modified Bessel function with parameter $\rho$ and $\Gamma(\cdot)$ denotes the gamma function.

In the remainder, let $C S_{m o n}$ and $W_{m o n}$ denote the present value of the infinite flow of consumer surplus and the ex ante expected total surplus, respectively, in the case of a monopolist. The critical level of investment for the monopoly case is obtained from Thijssen et al. (2003). We use the economic situation described in Example 1, i.e. a new market model with affine demand and linear costs. Consider the parametrization as given in Table 3. From Example 1 we can conclude that 


\begin{tabular}{||l|r||}
\hline$Y=5$ & $r=0.1$ \\
\hline$c=2$ & $p_{0}=0.4$ \\
\hline$I=5$ & \\
\hline
\end{tabular}

Table 3: Parameter values.

the monopoly price is given by $P_{\text {mon }}=\frac{Y+c}{2}$, the price in case of simultaneous investment equals $P_{M}=\frac{Y+2 c}{3}$, and the price in the Stackelberg case is given by $P_{S}=\frac{Y+3 c}{4}$. Given that the market is good, the flow of consumer surplus is then represented by $\int_{P_{P}}^{Y} P^{-1}(p) d p=\frac{1}{2}\left(Y-P_{P}\right)^{2}$, where $P_{P}$ is the equilibrium price. Hence, $C S_{\text {mon }}^{H}=\int_{0}^{\infty} e^{-r t} \frac{1}{2}\left(Y-P_{\text {mon }}\right)^{2} d t=\frac{\left(Y-P_{\text {mon }}\right)^{2}}{8 r}$. Similarly, $C S_{M}^{H}=\frac{\left(Y-P_{M}\right)^{2}}{6 r}$, $C S_{S}^{H}=\frac{\left(Y-P_{S}\right)^{2}}{32 r}$, and $C S_{m o n}^{L}=C S_{M}^{L}=C S^{L}=0$.

We want to analyse the effect of the quantity and quality of information on welfare in both the monopolistic and the duopoly case. First, consider the case where $\lambda=0.6$ and $\mu$ varies from 2 up to 5. Calculations lead to Figure 2. As can

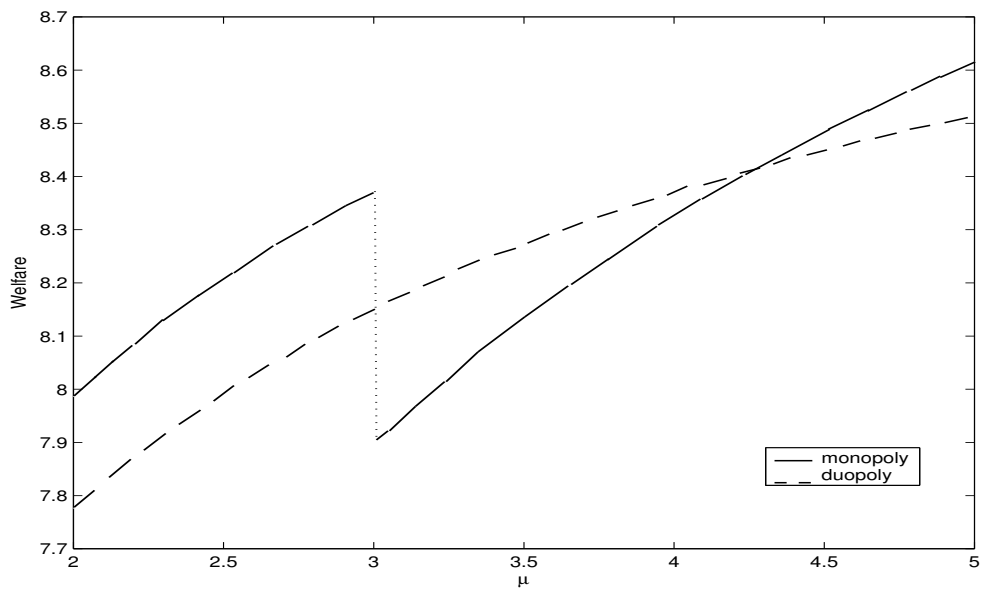

Figure 2: Welfare as a function of $\mu$.

be seen from the figure, one cannot derive a clear-cut result saying that competition is better than monopoly or vice versa. This is caused by the discreteness of the investment threshold. In the duopoly case a Stackelberg equilibrium arises for all values of $\mu$, while the investment threshold always equals $\left\lceil k_{d}\right\rceil=1$. From (4) one can see that $p_{P}$ is independent of both $\mu$ and $\lambda$ and that $k(p)$ is independent of $\mu$. Hence, $\left\lceil k_{d}\right\rceil$ cannot differ for varying values of $\mu$. As $\mu$ increases welfare improves, because more information is (in this case) better. The jump in the curve for welfare under monopoly occurs because at $\mu \approx 3$ the investment threshold $\left\lceil k_{m}\right\rceil$ jumps from 1 to 2 . This happens since $k_{m}$ is increasing in $\mu$, which implies that $\left\lceil k_{m}\right\rceil$ exhibits upward jumps for some values of $\mu$, while it is constant otherwise. As soon as there 
is a jump, the monopolist waits longer, which reduces both the risk of investing in a bad market as well as expected consumer surplus. From the above it becomes clear that the latter effect dominates, implying that the intuition that more information is always better cannot be sustained.

Secondly, we analyse the effect of the quality of information on welfare by taking $\mu=4$ and by letting $\lambda$ vary from 0.55 to 0.8 . This yields Figure 3 . The jumps occur

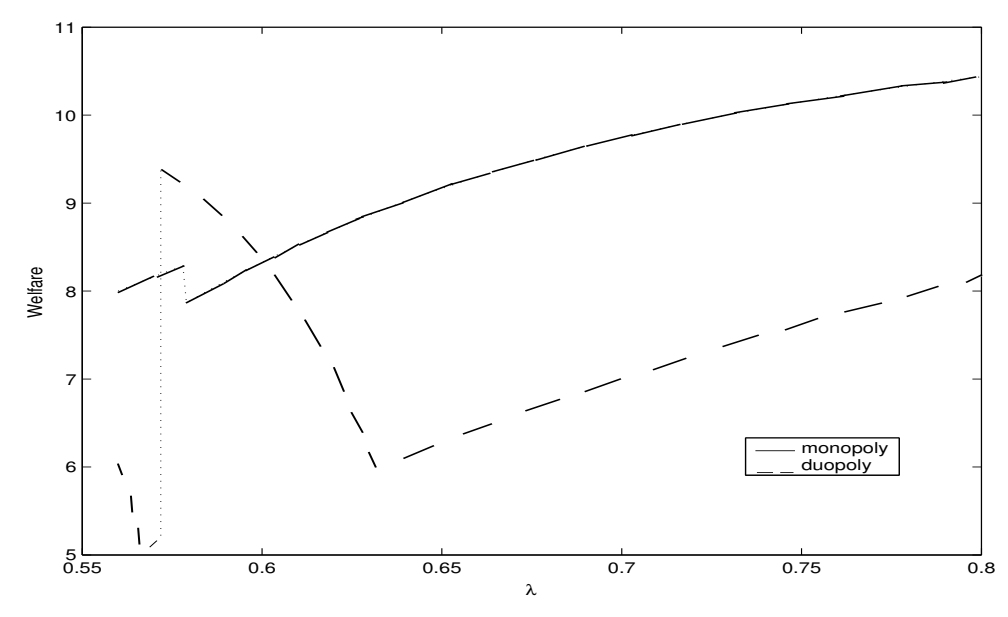

Figure 3: Welfare as a function of $\lambda$.

due to the discreteness of the investment threshold just as before. We will describe monopoly and duopoly separately to get some feeling for the different effects at work. First, let us consider the monopoly case. At $\lambda \approx 0.575,\left\lceil k_{m}\right\rceil$ jumps from 1 to 2 , which accounts for the drop in welfare. For the remainder of the domain, an increase in $\lambda$ reduces the risk of investment while the market is bad and accelerates investment, which results in increasing expected consumer and producer surplus and thus in higher welfare levels.

In the duopoly case there are more effects. The jump at $\lambda \approx 0.57$ occurs since $\left\lceil k_{d}\right\rceil$ jumps from 2 to 1 (although $p_{P}$ remains constant), since less signals are needed to reach $p_{P}$. This is good for expected consumer surplus, hence the increase. For $\lambda$ between 0.57 and 0.635 , a Stackelberg or a Cournot equilibrium arises. Welfare decreases over this range since for increasing $\lambda$ the probability of simultaneous investment at the preemption point increases monotonically. ${ }^{9}$ In case of simultaneous investment both firms do not wait for the outcome of the other firm's investment. Hence, they both invest without knowing beforehand the state of the market. This implies that in case of a bad market the sunk investment costs is lost twice for the whole market. Therefore, the loss (due to sunk investment costs) in case the mar-

\footnotetext{
${ }^{9}$ This is not an analytical result. The probability of simultaneous investment can also decrease with increasing $\lambda$.
} 
ket turns out to be bad is increasing in $\lambda$ which has a negative effect on welfare. From $\lambda \approx 0.635$ onwards, a Cournot equilibrium arises where both firms always invest simultaneous. Higher $\lambda$ means that signals are more reliable. Therefore, the probability of simultaneous investment in a bad market is smaller, which increases expected producer surplus and thus enhances expected welfare, although the welfare level is lower than under monopoly.

A final remark concerns the range where $\lambda$ is in between 0.55 and 0.65 . Here $\left\lceil k_{m}\right\rceil=1$ and $\left\lceil k_{d}\right\rceil=2$, i.e. in a monopolistic market investment takes place at an earlier date than in a duopoly, given an identical sample path of the information process. This is due to the fact that the discounted value of the project is higher for a monopolist than for a firm that faces competition. This higher discounted value has a dampening effect on the waiting time.

From these examples two observations can be made. Firstly, more or better information does not always lead to higher welfare. This is mainly due to opposing effects influencing the expected producer surplus. Expected consumer surplus in general increases in the quality and quantity of information. An exception arises in the monopoly case where the threshold level $\left\lceil k_{m}\right\rceil$ can jump upwards. This happens because of the fact that the increase in the value of waiting delays investment, which is bad for consumer surplus. In the duopoly case there is another effect regarding the quality of information. In a range where both a Stackelberg and a Cournot-Nash equilibrium can occur the probability of joint investment at the preemption point can increase, if information gets qualitatively better. This has a negative influence on producer surplus, since if the market turns out to be bad both firms will lose the sunk costs $I$. The magnitude of these sunk-costs might not offset the increase in expected consumer surplus due to earlier investment.

The second observation is that it is not clear whether a monopolistic or an oligopolistic market structure is desirable from an ex ante social welfare perspective. To get a better insight in this problem, consider an example with $Y=60, c=20$, $I=500, p_{0}=0.4$ and $r=0.1$. We take $\mu \in[0.5,4]$ and $\lambda \in[0.6,0.9]$ and compare welfare for monopoly and duopoly. This is depicted in Figure 4. From the figure one gets the impression that "bad" information (i.e. low $\mu$ and low $\lambda$ ) seems to favour a duopolistic structure, whereas "good" information (i.e. high $\mu$ and high $\lambda$ ) seems to favour a monopolistic market structure.

To test this hypothesis we simulate the model. In each run we sample $(Y-c) \sim$ $U[5,50]$, where $\mathcal{U}$ denotes the uniform distribution and $I \sim \mathcal{U}\left[\frac{1}{4} U_{F}^{H}, \frac{3}{4} U_{F}^{H}\right]$. The interest rate is set to $r=0.1$ and the prior belief in a good market at $p_{0}=$ 0.4. We sample 1000 instances of "bad" information with $\mu^{L} \sim \mathcal{U}[0.5,1.5]$ and $\lambda^{L} \sim \mathcal{U}[0.6,0.7]$, and 1000 instances of "good" information with $\mu^{H} \sim \mathcal{U}[3,4]$ and 


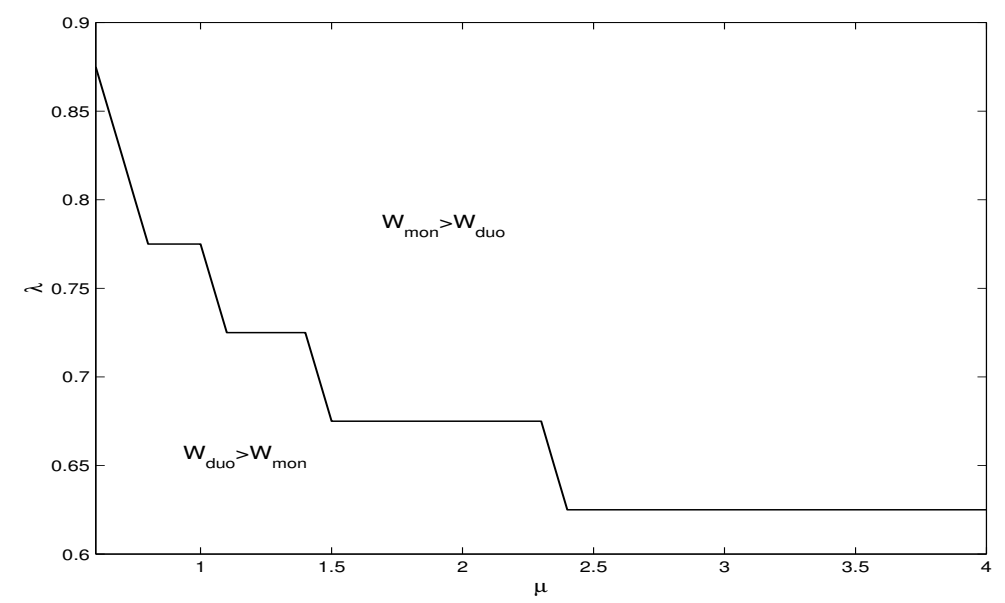

Figure 4: Regions of higher welfare (monopoly or duopoly) for different $(\mu, \lambda)$ combinations. $W_{\text {mon }}\left(W_{d u o}\right)$ denotes welfare in the monopoly (duopoly) case.

$\lambda^{H} \sim \mathcal{U}[0.8,0.9]$. This leads to four series of simulated expected ex ante welfare levels for monopoly and duopoly, $W_{m o n}^{L}, W_{d u o}^{L}, W_{m o n}^{H}$, and $W_{d u o}^{H}$. Since we hypothesise that $\mathbb{E}\left(W_{\text {duo }}^{L}\right)>\mathbb{E}\left(W_{\text {mon }}^{L}\right)$ and $\mathbb{E}\left(W_{\text {mon }}^{H}\right)>\mathbb{E}\left(W_{\text {duo }}^{H}\right)$, we test the null-hypotheses $H_{0}: \mathbb{E}\left(W_{d u o}^{L}-W_{m o n}^{L}\right) \leq 0$ and $H_{0}: \mathbb{E}\left(W_{m o n}^{H}-W_{d u o}^{H}\right) \leq 0$. Using standard asymptotically normal tests, both null-hypotheses are rejected at $5 \% .{ }^{10}$ So, we find evidence that a duopoly leads to a significantly higher level of expected ex ante welfare than monopoly if the information is relatively bad, whereas the reverse holds if information is relatively good. Intuitively, one can see that if information is bad, the value to wait for a monopolist is very low. Therefore, he will invest soon. On the other hand, in the duopoly case, although the preemption level may be reached soon, the probability of joint investment is low and this dampens the negative preemptive effect on expected producer surplus. If information is good, firms are more likely to simultaneously invest which is bad for expected producer surplus. So, in expectation the preemption effect "hurts" more if information is good. Moreover, the value of waiting increases when signals become more valuable, or occur more frequently. In the monopoly case this value of waiting is fully taken into account, whereas in a duopoly firms still intend to invest quickly to preempt their rival.

In the above analysis only the preemption case is considered. From a mathematical point of view the advantage of considering the preemption case is that one knows that the game stops as soon as the preemption level is reached. This allows for the

\footnotetext{
${ }^{10}$ Let $\left(x_{1}, \ldots, x_{n}\right)$ be a sample of iid draws with $\mathbb{E}(x)=\mu, \operatorname{Var}(x)=\sigma^{2}$, sample mean $\bar{x}$, and sample variance $\hat{\sigma}^{2}$. For testing $H_{0}: \mu \leq 0$ we use the test statistic $T=\frac{\sqrt{n} \bar{x}}{\hat{\sigma}^{2}}$, which under the null-hypothesis has a standard normal distribution. In our case we get $T=4.45$ and $T=30.60$, respectively.
} 
use of the distribution of the first passage time in the definition of ex ante expected total surplus. In case the information spillover outweighs the Stackelberg effect a war of attrition arises. To make a comparable welfare analysis for this case one has to consider all possible paths for the arrival of signals before the preemption region is hit. So, not only the distribution for the first passage time, but the distribution of second, third, etc. passage times for values $k \in K$ have to be considered, conditional on the fact that the preemption value is not reached. Such an analysis is not analytically tractable. However, one could estimate the ex ante expected total surplus by use of simulations. Also in this case ambiguous results regarding the welfare effects of monopoly and duopoly can be expected, depending on the position of the critical investment level for a monopolist relative to $p_{L}$. An additional effect concerning the welfare comparison of monopoly and duopoly in case of a war of attrition is the free rider effect. In a duopoly both firms like the other to invest first so that it does not need to take the risk that the project has low value. Consequently firms invest too late, leading to a lower expected consumer surplus.

\section{Conclusions}

Non-exclusivity is a main feature that distinguishes real options from their financial counterparts (Zingales (2000)). A firm having a real investment opportunity often shares this possibility with one or more competitors and this has a negative effect on profits. The implication is that, to come to a meaningful analysis of the value of a real option, competition must be taken into account.

This paper considers a duopoly where both firms have the same possibility to invest in a new market with uncertain payoffs. As time passes uncertainty is gradually resolved by the arrival of new information regarding the quality of the investment project in the form of signals. Generally speaking, each firm has the choice of being the first or second investor. A firm moving first reaches a higher market share by having a Stackelberg advantage. However, being the second investor implies that the investment can be undertaken knowing the payoff with certainty, since by observing the performance in the market of the first investor it is possible to obtain full information regarding the quality of the investment project.

The outcome mainly depends on the speed at which information arrives over time. If the quality and quantity of the signals is sufficiently high, the information advantage of the second investor is low so that the Stackelberg advantage of the first investor dominates, which always results in a preemption game. In the other scenario, initially a war of attrition prevails where it is preferred to wait for the competitor to undertake the risky investment. During the time where this war of 
attrition goes on it happens with positive probability that both firms refrain from investment. It can then be the case that so many bad signals arrive that the belief in a good project again becomes so low that the war of attrition is ended and that no firm invests for the time being. On the other hand, it can happen that so many positive signals in excess of bad signals arrive that at some point in time the Stackelberg advantage starts to exceed the value of the information spillover. This then implies that the war of attrition turns into a preemption game.

From the industrial organisation literature it is known that a monopoly is bad for social welfare. In our model the welfare issue is more complicated, mainly because we look at expected ex ante social welfare. We find evidence that a duopolistic market structure is more desirable in cases where there is few and qualitatively poor information. On the other hand, a monopolistic market structure is better if quantity and quality of information are high. The main reasons for this conclusion are, firstly, the low expected producer surplus in the duopoly case due to a high probability of simultaneous investment, resulting in a higher probability that both firms loose the sunk investment costs. Secondly, if a lot of information arrives over time (in expectation) the value of postponing investment increases. However, in a duopoly framework the presence of competition still makes that investment takes place soon. Furthermore, we show that more or better information does not necessarily lead to higher expected welfare. In the monopoly case this is mainly due to the fact that, again, more signals arriving over time raises the value of waiting. Therefore, the monopolist delays investment, which is bad for consumer surplus. In the duopoly case the resulting equilibrium market structure (Stackelberg or Cournot) plays an important role.

Finally, departing from the modelling framework of this paper two interesting topics for future research can be distinguished. Firstly, one could include the possibility for firms to invest in the quantity and quality of the signals. This would then give rise to an optimal R\&D model, that also includes the problem of optimal sampling. Secondly, it is interesting to allow for entry and exit in this model. This would then lead to an analysis of the optimal number of firms from a social welfare perspective, thereby making it possible to compare with existing literature like e.g. Mankiw and Whinston (1986). 


\section{Appendix}

\section{A Equilibrium Concepts for Timing Games}

In this appendix we briefly review the appropriate equilibrium concepts for game theoretic real option models that are developed in Thijssen et al. (2002). Let $\left(\Omega, \mathcal{F},\left(\mathcal{F}_{t}\right)_{0 \leq t \leq \infty}, P\right)$ be a filtered probability space satisfying the usual hypotheses, i.e. $\mathcal{F}_{0}$ contains all the $P$-null sets of $\mathcal{F}$ and the filtration $\left(\mathcal{F}_{t}\right)_{0 \leq t \leq \infty}$ is rightcontinuous $^{11}$. Let $\left(Y_{t}\right)_{t \geq 0}$ be a semimartingale on this filtered probability space.

First we define a simple strategy for the subgame starting at $t_{0}$.

Definition $1 A$ simple strategy for player $i \in\{1,2\}$ in the subgame starting at $t_{0} \in[0, \infty)$ is given by a tuple of real-valued functions $\left(G_{i}^{t_{0}}, \alpha_{i}^{t_{0}}\right):\left[t_{0}, \infty\right) \times \Omega \rightarrow$ $[0,1] \times[0,1]$, such that for all $\omega \in \Omega$

1. $G_{i}^{t_{0}}(\cdot, \omega)$ is non-decreasing and right-continuous with left limits;

2. $\alpha_{i}^{t_{0}}(\cdot, \omega)$ is right-continuous with left limits;

3. if $\alpha_{i}^{t_{0}}(t, \omega)=0$ and $t=\inf \left\{u \geq t_{0} \mid \alpha_{i}^{t_{0}}(u, \omega)>0\right\}$, then the right-derivative of $\alpha_{i}^{t_{0}}(t, \omega)$ exists and is positive.

Denote for all $\omega \in \Omega$ the strategy set of simple strategies of player $i$ in the subgame starting at $t_{0} \geq 0$ by $S_{i}^{s}\left(t_{0}, \omega\right)$. Furthermore, define the strategy space by $S^{s}\left(t_{0}, \omega\right)=$ $\prod_{i=1,2} S_{i}^{s}\left(t_{0}, \omega\right)$ and denote the strategy at $t \in\left[t_{0}, \infty\right)$ by $s^{t_{0}}(t, \omega)=\left(G_{i}^{t_{0}}(t, \omega)\right.$, $\left.\alpha_{i}^{t_{0}}(t, \omega)\right)_{i=1,2}$.

For all $\omega \in \Omega$, the function $G_{i}^{t_{0}}$ is a cumulative distribution function where $G_{i}^{t_{0}}(t, \omega)$ is the probability that firm $i$ has invested before or at time $t$. The function $\alpha_{i}^{t_{0}}(\cdot, \omega)$ is called the atom function and it describes a sequence of atoms. The atom function allows for coordination between firms in cases where investment by at one firm is optimal, but simultaneous investment is not. The atom function replicates discrete time results that are lost by modelling in continuous time. Briefly stated, as soon as the atom function is non-zero a game is played where both players invest with probability $\alpha_{i}$ and $\alpha_{j}$, respectively. This game is repeated until at least one firm invests. Let for all $\omega \in \Omega$ and $t_{0} \geq 0, \tau$ be defined as

$$
\tau=\min _{i=1,2}\left\{\inf \left\{t \geq t_{0} \mid \alpha_{i}^{t_{0}}(t, \omega)>0\right\}\right\}
$$

If one denotes by $\mathbb{P}(i \mid \tau)$ the probability that firm $i$ invests at time $\tau$ and by $\mathbb{P}(i, \neg j \mid \tau)$ that firm $i$ invests at time $\tau$ but firm $j$ does not, the following probabilities that are

\footnotetext{
${ }^{11} \mathcal{F}_{t}=\bigcap_{u>t} \mathcal{F}_{u}$, all $t, 0 \leq t<\infty$
} 
needed in the proofs of the propositions are obtained,

$$
\begin{aligned}
\mathbb{P}(i, \neg j \mid \tau) & =\frac{\alpha_{i}^{t_{0}}(\tau, \omega)\left(1-\alpha_{j}^{t_{0}}(\tau, \omega)\right)}{\alpha_{i}^{t_{0}}(\tau, \omega)+\alpha_{j}^{t_{0}}(\tau, \omega)-\alpha_{i}^{t_{0}}(\tau, \omega) \alpha_{j}^{t_{0}}(\tau, \omega)}, \\
\mathbb{P}(j, \neg i \mid \tau) & =\frac{\left(1-\alpha_{i}^{t_{0}}(\tau, \omega)\right) \alpha_{j}^{t_{0}}(\tau, \omega)}{\alpha_{i}^{t_{0}}(\tau, \omega)+\alpha_{j}^{t_{0}}(\tau, \omega)-\alpha_{i}^{t_{0}}(\tau, \omega) \alpha_{j}^{t_{0}}(\tau, \omega)}, \\
\mathbb{P}(i, j \mid \tau) & =\frac{\alpha_{i}^{t_{0}}(\tau, \omega) \alpha_{j}^{t_{0}}(\tau, \omega)}{\alpha_{i}^{t_{0}}(\tau, \omega)+\alpha_{j}^{t_{0}}(\tau, \omega)-\alpha_{i}^{t_{0}}(\tau, \omega) \alpha_{j}^{t_{0}}(\tau, \omega)}, \\
\mathbb{P}(i \mid \tau) & =\frac{\alpha_{i}^{t_{0}}(\tau, \omega)}{\alpha_{i}^{t_{0}}(\tau, \omega)+\alpha_{j}^{t_{0}}(\tau, \omega)-\alpha_{i}^{t_{0}}(\tau, \omega) \alpha_{j}^{t_{0}}(\tau, \omega)} .
\end{aligned}
$$

The definition of simple strategies does not a priori exclude the possibility that both firms choose an atom function that turns out to be inconsistent with the cumulative distribution function $G^{t_{0}}(\cdot, \omega)$. In equilibrium it should naturally be the case that inconsistencies of this kind do not occur. Therefore, we introduce the notion of $\alpha$-consistency.

Definition 2 A tuple of simple strategies $\left(\left(G_{i}^{t_{0}}, \alpha_{i}^{t_{0}}\right)\right)_{i=1,2}$ for the subgame starting at $t_{0} \geq 0$ is $\alpha$-consistent if for $i=1,2$ it holds that for all $\omega \in \Omega$ and $t \geq t_{0}$,

$$
\begin{aligned}
\alpha_{i}^{t_{0}}(t, \omega) & -\alpha_{i}^{t_{0}}(t-, \omega) \neq 0 \Rightarrow G_{i}^{t_{0}}(t, \omega)-G_{i}^{t_{0}}(t-, \omega)= \\
& =\left(1-G_{i}^{t_{0}}(t-, \omega)\right) \frac{\alpha_{i}^{t_{0}}(t, \omega)}{\alpha_{i}^{t_{0}}(t, \omega)+\alpha_{j}^{t_{0}}(t, \omega)-\alpha_{i}^{t_{0}}(t, \omega) \alpha_{j}^{t_{0}}(t, \omega)} .
\end{aligned}
$$

An $\alpha$-equilibrium for the subgame starting at $t_{0} \geq 0$ is then defined as follows.

Definition 3 A tuple of simple strategies $s^{*}=\left(s^{*}(\omega)\right)_{\omega \in \Omega}, s^{*}(\omega) \in S^{s}\left(t_{0}, \omega\right)$, all $\omega \in \Omega$, is an $\alpha$-equilibrium for the subgame starting at $t_{0}$ if for all $\omega \in \Omega, s^{*}(\omega)$ is $\alpha$-consistent and

$$
\forall_{i \in\{1,2\}} \forall_{s_{i} \in S_{i}^{s}\left(t_{0}, \omega\right)}: V_{i}\left(t_{0}, s^{*}(\omega)\right) \geq V_{i}\left(t_{0}, s_{i}, s_{-i}^{*}(\omega)\right) .
$$

A problem with $\alpha$-equilibrium is that it does not exclude time inconsistent strategies. To rule these out we need the notion of closed loop strategy.

Definition 4 A closed loop strategy for player $i \in\{1,2\}$ is for all $\omega \in \Omega$ a collection of simple strategies

$$
\left(\left(G_{i}^{t}(\cdot, \omega), \alpha_{i}^{t}(\cdot, \omega)\right)\right)_{0 \leq t<\infty},
$$

with $\left(G_{i}^{t}(\cdot, \omega), \alpha_{i}^{t}(\cdot, \omega)\right) \in S_{i}^{s}(t, \omega)$ for all $t \geq 0$ that satisfies the following intertemporal consistency conditions for all $\omega \in \Omega$ :

1. $\forall_{0 \leq t \leq u \leq v<\infty}: v=\inf \left\{\tau>t \mid Y_{\tau}=Y_{v}\right\} \Rightarrow G_{i}^{t}(v, \omega)=G_{i}^{u}(v, \omega)$;

2. $\forall_{0 \leq t \leq u \leq v<\infty}: v=\inf \left\{\tau>t \mid Y_{\tau}=Y_{v}\right\} \Rightarrow \alpha_{i}^{t}(v, \omega)=\alpha_{i}^{u}(v, \omega)$. 
The set of closed loop strategies for player $i \in\{1,2\}$ is denoted by $S_{i}^{c l}(\omega)$. As before, we define the strategy space to be $S^{c l}(\omega)=\prod_{i \in\{1,2\}} S_{i}^{c l}(\omega)$.

A consistent $\alpha$-equilibrium is now defined as follows.

Definition 5 A tuple of closed loop strategies $\bar{s}=(\bar{s}(\omega))_{\omega \in \Omega}, \bar{s}(\omega) \in S^{c l}(\omega)$, all $\omega \in \Omega$, is a consistent $\alpha$-equilibrium if for all $t \in[0, \infty)$, the corresponding tuple of simple strategies $\left(\left(G_{1}^{t}, \alpha_{1}^{t}\right),\left(G_{2}^{t}, \alpha_{2}^{t}\right)\right)$ is an $\alpha$-equilibrium for the subgame starting at $t$.

\section{B Proof of Proposition 1}

Let $\left(\Omega, \mathcal{F},\left(\mathcal{F}_{t}\right)_{t \geq 0}, P\right)$ be the filtered probability space underlying the stochastic process governing the arrival of signals. First notice that for each $\omega \in \Omega$ and $i=1,2$, the strategy $\left(G_{i}^{t}, \alpha_{i}^{t}\right)_{t \in[0, \infty)}$ satisfies the intertemporal consistency and $\alpha$-consistency conditions of Definitions 4 and 2, respectively. Hence, the closed loop strategies are well-defined. Let $t \in[0, \infty)$. It will be shown that $\left(G_{i}^{t}, \alpha_{i}^{t}\right)_{i=1,2}$ is an $\alpha$-equilibrium for the game starting at $t$. Due to discounting, it is a dominant strategy to invest with positive probability only at points in time when new information arrives. Since $p_{t}$ has non-continuous sample paths, due to the Poisson arrivals of signals, the cdf $G^{t}(\cdot)$ has to be a step function. We consider three cases.

1. $t=T_{M}^{t}$ (i.e. $p_{t} \geq p_{M}$ )

Given that firm $j$ plays its closed loop strategy, firm $i$ has three possible strategies. First, firm $i$ can play $G_{i}^{t}(t)=0$, i.e. it does not invest. Then firm $i$ 's expected payoff equals $F\left(p_{t}\right)$. If firm $i$ invests with an isolated atom equal to $\nu>0$, then the expected payoff equals $F\left(p_{t}\right)+\nu\left(M\left(p_{t}\right)-F\left(p_{t}\right)\right) \geq F\left(p_{t}\right)$. Finally, suppose that $\alpha_{i}^{t}(t)=a>0$. From (17) one can see that, since $\alpha_{j}^{t}(t)=$ 1 , the expected payoff for firm $i$ is given by

$$
\begin{aligned}
& \frac{1}{a+\alpha_{j}^{t}(t)-a \alpha_{j}^{t}(t)}\left(a\left(1-\alpha_{j}^{t}(t)\right) L\left(p_{t}\right)+(1-a) \alpha_{j}^{t}(t) F\left(p_{t}\right)+a \alpha_{j}^{t}(t) M\left(p_{t}\right)\right) \\
& =F\left(p_{t}\right)+a\left(M\left(p_{t}\right)-F\left(p_{t}\right)\right) \geq F\left(p_{t}\right) .
\end{aligned}
$$

So, maximizing the expected payoff gives $a=1$.

2. $t<T_{P}^{t}$ (i.e. $\left.p_{t}<p_{P}\right)$

Given the strategy of firm $j$, if firm $i$ does not invest, its value is $W\left(p_{t}\right)$. Since $T_{L} \geq T_{P}$, we know it is not optimal to invest yet. Hence, $W\left(p_{t}\right)>L\left(p_{t}\right)$. If firm $i$ invests with an isolated atom equal to $\nu>0$, then its expected payoff equals $W\left(p_{t}\right)+\nu\left(L\left(p_{t}\right)-W\left(p_{t}\right)\right) \leq W\left(p_{t}\right)$. Investing with an interval of atoms, i.e. $\alpha_{i}^{t}(t)=a>0$, gives an expected payoff equal to $L\left(p_{t}\right)$. Hence it is optimal to set $G_{i}^{t}(t)=0$. 
3. $t=T_{P}^{t}<T_{M}^{t}$ (i.e. $p_{P} \leq p_{t}<p_{M}$ )

Investing with probability zero, i.e. $G_{i}^{t}(t)=0$ yields an expected payoff equal to $F\left(p_{t}\right)$, given that firm $j$ plays its strategy, i.e. $G_{i}^{t}(t)=1$. If firm $i$ invests with an isolated jump equal to $\nu>0$, then

$\mathbb{P}$ (both firms invest simultaneously $)=\nu \alpha_{j}^{t}(t)$,

$\mathbb{P}($ firm $i$ invests first $)=\nu\left(1-\alpha_{j}^{t}(t)\right)$,

$\mathbb{P}($ firm $j$ invests first $)=1-\nu$.

Given $\alpha_{j}^{t}(t)=\frac{L(t)-F(t)}{L(t)-M(t)}$ the expected payoff for firm $i$ is given by

$$
\nu \alpha_{j}^{t}(t) M\left(p_{t}\right)+\nu\left(1-\alpha_{j}^{t}(t)\right) L\left(p_{t}\right)+(1-\nu) F\left(p_{t}\right)=F\left(p_{t}\right) .
$$

Finally, if firm $i$ plays $\alpha_{i}^{t}(t)=a>0$, then the expected payoff is given by

$$
\begin{aligned}
& \frac{1}{a+\alpha_{j}^{t}(t)-a \alpha_{j}^{t}(t)}\left(a \alpha_{j}^{t}(t) M\left(p_{t}\right)+a\left(1-\alpha_{j}^{t}(t)\right) L\left(p_{t}\right)+(1-a) \alpha_{j}^{t}(t) F\left(p_{t}\right)\right) \\
& =F\left(p_{t}\right) .
\end{aligned}
$$

From these cases we deduce that unilateral deviations do not yield higher expected profits, which proves the proposition.

\section{Proof of Lemma 1}

It is easy to see that the war of attrition region $K$ is finite with cardinality, say, $n$. Hence, the system in (13) gives rise to a function $f: \mathbb{R}^{n} \rightarrow \mathbb{R}^{n}$ where the $k$-th entry is given by

$$
f_{k}(x)=a_{k} x_{k}+b_{k}-\left(1-x_{k}\right)\left(c_{k} x_{k+1}+d_{k} x_{k-1}-e_{k}\right), \quad k=1, \ldots, n .
$$

A solution for the system (13) is equivalent to $x \in \mathbb{R}^{n}$ such that $f(x)=0$.

Let $k \in K$ and let $x \in \mathbb{R}^{n}$ such that $x_{k}=1$ be fixed. We have

$$
f_{k}(x)=a_{k}+b_{k}=M(k)-L(k)-F(k)+L(k)<0,
$$

since we are in the attrition region.

Furthermore, note that

$$
\begin{aligned}
b_{k}-e_{k}= & \frac{\lambda^{k}}{\lambda^{k}+\zeta(1-\lambda)^{k}}\left(U_{L}^{H} \frac{\mu}{r+\mu}\left(\lambda U_{L}^{H}+(1-\lambda) U_{L}^{H}\right)\right) \\
& -\left(1-\frac{\mu}{r+\mu} \frac{\lambda^{k+1}+\zeta(1-\lambda)^{k+1}+\lambda(1-\lambda)\left(\lambda^{k-1}+\zeta(1-\lambda)^{k-1}\right)}{\lambda^{k}+\zeta(1-\lambda)^{k}}\right) I \\
= & \frac{\mu}{r}\left(p(k) U_{L}^{H}-I\right)=\frac{\mu}{r} L(k)>0 .
\end{aligned}
$$


Using this observation we obtain that if $x \in \mathbb{R}^{n}$ is such that $x_{k}=0$,

$$
\begin{aligned}
f_{k}(x)= & b_{k}-e_{k}-c_{k} x_{k+1}-d_{k} x_{k-1} \\
= & \frac{\mu}{r} L(k)-\frac{\mu}{r+\mu} \frac{\lambda^{k+1}+\zeta(1-\lambda)^{k+1}}{\lambda^{k}+\zeta(1-\lambda)^{k}} x_{k+1}(M(k+1)-L(k+1)) \\
& -\frac{\mu}{r+\mu} \frac{\lambda^{k-1}+\zeta(1-\lambda)^{k-1}}{\lambda^{k}+\zeta(1-\lambda)^{k}} x_{k-1}(M(k-1)-L(k-1)) \\
& >0
\end{aligned}
$$

since $M(k) \leq L(k)$ for all $k \leq\left\lceil k_{P}\right\rceil$.

Hence, for all $k \in K$ and all $x \in \mathbb{R}^{n}$ we have $x_{k}=0 \Rightarrow f_{k}(x)>0$ and $x_{k}=1 \Rightarrow f_{k}(x)<0$. Since $[0,1]^{n}$ is a convex and compact set and $f(\cdot)$ is continuous on $[0,1]^{n}$, there exists a stationary point $x^{*} \in[0,1]$, i.e. for all $x \in[0,1]^{n}$ it holds that $x f\left(x^{*}\right) \leq x^{*} f\left(x^{*}\right)$.

Let $k \in\{1, \ldots, n\}$. Suppose that $x_{k}^{*}>0$. Then there exists an $\varepsilon>0$ such that $x=x^{*}-\varepsilon 1_{k} \in[0,1]^{n}$, where $1_{k}$ denotes the $k$-th unity vector. This gives $f_{k}\left(x^{*}\right) \geq 0$. Similarly, if $x_{k}^{*}<1$ there exists an $\varepsilon>0$ such that $x=x^{*}+\varepsilon 1_{k} \in[0,1]^{n}$. Since $x^{*}$ is a stationary point this yields $f_{k}\left(x^{*}\right) \leq 0$. Hence, if $0<x_{k}^{*}<1$ this implies that $f_{k}\left(x^{*}\right)=0$. Now suppose that $x_{i}^{*}=0$. Then $f_{k}\left(x^{*}\right) \leq 0$, which contradicts (19). Finally, suppose that $x_{i}^{*}=1$. Then $f_{k}\left(x^{*}\right) \geq 0$, which contradicts (18).

\section{Proof of Proposition 2}

By Lemma 1 there exists a $x \in[0,1]^{n}$ such that $f(x)=0$. For all $k \in K$, let $\gamma(k)=x_{k}$. Furthermore, it is easy to see that $\left(G_{i}^{t}, \alpha_{i}^{t}\right)_{i=1,2}$ satisfies the intertemporal and $\alpha$-consistency conditions for each $t \in[0, \infty)$.

We prove that for each subgame starting at $t$, the simple strategy $\left(G_{i}^{t}, \alpha_{i}^{t}\right)$ is an $\alpha$-equilibrium. The case where $t$ is such that $p_{t}<p_{L}$ is exactly the same as the case where $t<T_{P}^{t}<T_{M}^{t}$ in the proof of Proposition 1. The same holds true for the case where $t=T_{M}^{t}$. Consider the region for the war of attrition, i.e. $t$ is such that $p_{t} \in\left[p_{L}, p_{P}\right)$. Then $k_{t} \in K$. Suppose that firm $i$ invests with an interval of atoms and suppose $\alpha_{i}^{t}(t)=a$. Then given that firm $j$ invests with an isolated jump equal to $\gamma\left(k_{t}\right)$. In analogy of $(17)$ we get

$\mathbb{P}($ firm $i$ invests first $)=1-\gamma\left(k_{t}\right)$,

$\mathbb{P}($ firm $j$ invests first $)=\gamma\left(k_{t}\right)(1-a)$,

$\mathbb{P}($ firms invest simultaneously $)=a \gamma\left(k_{t}\right)$.

Hence, the expected payoff for firm $i$ is given by

$$
a \gamma_{j}\left(k_{t}\right) M\left(p_{t}\right)+\left(1-\gamma_{j}\left(k_{t}\right)\right) L\left(p_{t}\right)+\gamma_{j}\left(k_{t}\right)(1-a) F\left(p_{t}\right) .
$$


This expected payoff is maximised for $a=0$. Hence, firm $i$ will not play an interval of atoms. Suppose firm $i$ plays an isolated atom equal to $\nu \in[0,1]$. Then his expected payoff equals

$$
\nu V_{1}\left(p_{t}\right)+(1-\nu) V_{2}\left(p_{t}\right)
$$

and is hence independent of $\nu$ since, by definition, $\gamma_{j}\left(k_{t}\right)$ is such that $V_{1}\left(p_{t}\right)=V_{2}\left(p_{t}\right)$. Therefore, any $\nu \in[0,1]$, and in particular $\nu=\gamma\left(k_{t}\right)$, maximises the expected payoff.

\section{E Proof of Proposition 3}

The proof follows along the same lines as Feller (1971, Section 14.6). Note that the process starts at $t_{0}=0$ with $k_{0}=0$ a.s. Arriving at $k \neq 0$ at time $t>0$ can only be possible if a jump has occurred before $t$. Assume that the first jump occurred at time $t-x$. The conditional probability of the position $k \neq 0$ at time $t$ is denoted by $P_{k}(t)$. It is the convolution of the probability that the process was at $k+1$ at time $x$ or at $k-1$ at time $x$ and the probability of an arrival of an $l$-signal or an $h$-signal, respectively. Since the arrival of signals follows a Poisson process with parameter $\mu$ and hence the inter-arrival times are exponentially distributed with parameter $\mu$, $P_{k}(t)$ is given by

$$
P_{k}(t)=\int_{0}^{t} \mu e^{-\mu(t-x)}\left[q_{1}(k-1) P_{k-1}(x)+q_{2}(k+1) P_{k+1}(x)\right] d x,
$$

where

$$
q_{1}(k-1)=\frac{\lambda^{k}+\zeta(1-\lambda)^{k}}{\lambda^{k-1}+\zeta(1-\lambda)^{k-1}}
$$

is the probability of reaching state $k$ from state $k-1$ and

$$
q_{2}(k+1)=\lambda(1-\lambda) \frac{\lambda^{k}+\zeta(1-\lambda)^{k}}{\lambda^{k+1}+\zeta(1-\lambda)^{k+1}},
$$

is the probability of reaching state $k$ from state $k+1$. That is, $P_{k}(t)$ is the convolution of the distribution of reaching $k+1$ or $k-1$ at time $t-x$ and the distribution of the arrival of one signal in the interval $(t-x, t]$. For $k=0$, the probability of no jump up to $t, 1-\int_{0}^{t} \mu e^{-\mu t} d t=e^{-\mu t}$ must be added, i.e.

$$
P_{0}(t)=e^{-\mu t}+\int_{0}^{t} \mu e^{-\mu(t-x)}\left[q_{1}(-1) P_{-1}(x)+q_{2}(1) P_{1}(x)\right] d x,
$$

Denoting the Laplace transform of $P_{k}(\cdot)$ by $\pi_{k}(\cdot)$ we get from eqs. (20) and (23)

$$
\begin{aligned}
& \pi_{k}(\gamma)=\frac{\mu}{\mu+\gamma}\left[q_{1}(k-1) \pi_{k-1}(\gamma)+q_{2}(k+1) \pi_{k+1}(\gamma)\right] \quad \text { for } k \neq 0, \\
& \pi_{0}(\gamma)=\frac{1}{\mu+\gamma}+\frac{\mu}{\mu+\gamma}\left[q_{1}(-1) \pi_{-1}(\gamma)+q_{2}(1) \pi_{1}(\gamma)\right] .
\end{aligned}
$$


By substituting eqs. (21) and (22) into eq. (24) one obtains the following second order linear difference equation

$$
\mu \lambda(1-\lambda) F_{k+1}(\gamma)-(\mu+\gamma) F_{k}(\gamma)+\mu F_{k-1}(\gamma)=0
$$

where

$$
F_{k}(\gamma)=\frac{\pi_{k}(\gamma)}{\lambda^{k}+\zeta(1-\lambda)^{k}}
$$

The roots of the characteristic equation of eq. (26) are

$$
\beta_{\gamma}=\frac{\mu+\gamma-\sqrt{(\mu+\gamma)^{2}-4 \mu^{2} \lambda(1-\lambda)}}{2 \mu \lambda(1-\lambda)}
$$

and

$$
\begin{aligned}
\sigma_{\gamma} & =\frac{\mu+\gamma+\sqrt{(\mu+\gamma)^{2}-4 \mu^{2} \lambda(1-\lambda)}}{2 \mu \lambda(1-\lambda)} \\
& =\frac{4 \mu^{2} \lambda(1-\lambda)}{2 \mu \lambda(1-\lambda)\left(\mu+\gamma-\sqrt{(\mu+\gamma)^{2}-4 \mu^{2} \lambda(1-\lambda)}\right)} \\
& =\frac{1}{\lambda(1-\lambda)} \beta_{\gamma}^{-1} .
\end{aligned}
$$

The general solution for $k \neq 0$ is therefore given by

$$
F_{k}(\gamma)=A_{\gamma} \beta_{\gamma}^{k}+\frac{1}{\lambda(1-\lambda)} B_{\gamma} \beta_{\gamma}^{-k}
$$

Note that for $k \geq 0$ it holds that $\beta_{\gamma}^{k} \rightarrow 0$ as $\gamma \rightarrow \infty$, but that $\sigma_{\gamma}^{k} \rightarrow \infty$ as $\gamma \rightarrow \infty$. Since $\pi_{k}(\gamma)$ and hence $F_{k}(\gamma)$ are bounded as $\gamma \rightarrow \infty$, we get for $k \geq 0$ that $B_{\gamma}=0$. Similarly, we get for $k \leq 0$ that $A_{\gamma}=0$. So, a solution to eq. (26) is given by

$$
F_{k}(\gamma)= \begin{cases}F_{0}(\gamma) \beta_{\gamma}^{k} & k \geq 0 \\ \frac{1}{\lambda(1-\lambda)} F_{0}(\gamma) \beta_{\gamma}^{-k} & k<0\end{cases}
$$

and hence,

$$
\pi_{k}(\gamma)= \begin{cases}\frac{\lambda^{k}+\zeta(1-\lambda)^{k}}{1+\zeta} \beta_{\gamma}^{k} \pi_{0}(\gamma) & k \geq 0 \\ \frac{\lambda^{k}+\zeta(1-\lambda)^{k}}{1+\zeta} \frac{1}{\lambda(1-\lambda)} \beta_{\gamma}^{-k} \pi_{0}(\gamma) & k<0\end{cases}
$$

Solving for $\pi_{0}(\gamma)$ using eq. (25) gives

$$
\pi_{0}(\gamma)=\frac{1}{\beta_{\gamma}} \frac{\lambda(1-\lambda)}{(\mu+\gamma) \lambda(1-\lambda)-\mu\left(1+\lambda^{2}(1-\lambda)^{2}\right)} .
$$

Hence, eq. (27) is well-defined.

If at time $t$ the process is at $k \geq 0$, the first passage through $k$ must have occurred at time $\tau \leq t$. In this case, the conditional probability of being at $k$ again at time 
$t$ equals the probability of being at state 0 at time $t-\tau$ times the probability of a first passage through $k$ at time $\tau$, i.e.

$$
P_{k}(t)=\int_{0}^{t} F_{k}(\tau) P_{0}(t-\tau) d \tau
$$

where $F_{k}(\cdot)$ is the distribution of the first passage time through $k$. The Laplace transform of eq. (28) is given by

$$
\pi_{k}(\gamma)=f_{k}(\gamma) \pi_{0}(\gamma)
$$

From eq. (27) we therefore conclude that the Laplace transform of $F_{k}(\cdot)$ equals $f_{k}(\gamma)=\frac{\lambda^{k}+\zeta(1-\lambda)^{k}}{1+\zeta} \beta_{\gamma}^{k}$. Feller (1971) shows that for $\gamma>1,\left(\gamma-\sqrt{\gamma^{2}-1}\right)^{k}$ is the Laplace transform of the density $\frac{k}{t} I_{k}(t)$. Applying the mapping $\gamma \mapsto \frac{\gamma}{2 \mu \sqrt{\lambda(1-\lambda)}}$ is a change of scale and applying the mapping $\gamma \mapsto \gamma+\mu$ reflects multiplication of the density by $e^{-\mu t}$. Applying both mappings gives

$$
\begin{aligned}
\left(\gamma-\sqrt{\gamma^{2}-1}\right)^{k} & \mapsto\left(\frac{\gamma+\mu-\sqrt{(\gamma+\mu)^{2}-4 \mu^{2} \lambda(1-\lambda)}}{2 \mu \sqrt{\lambda(1-\lambda)}}\right)^{k} \\
& =\frac{\lambda^{k}+\zeta(1-\lambda)^{k}}{1+\zeta} \beta_{\gamma}^{k}\left(\frac{1+\zeta}{\lambda^{k}+\zeta(1-\lambda)^{k}}(\lambda(1-\lambda))^{k / 2}\right) .
\end{aligned}
$$

Hence, the pdf of the first passage time through $k$ is given by

$$
f_{k}(t)=\frac{\lambda^{k}+\zeta(1-\lambda)^{k}}{1+\zeta}(\lambda(1-\lambda))^{-k / 2} \frac{k}{t} I_{k}(2 \mu \sqrt{\lambda(1-\lambda)} t) e^{-\mu t},
$$

which proves the proposition.

\section{References}

Alvarez, L.H.R. and R. Stenbacka (2001). Adoption of Uncertain Multi-Stage Technology Projects: A Real Options Approach. Journal of Mathematical Economics, 35, 71-97.

Boyer, M. , P. Lasserre, T. Mariotti, and M. Moreaux (2001). Real Options, Preemption, and the Dynamics of Industry Investments. Mimeo, Université du Québec à Montréal, Montreal, Canada.

Décamps, J-P and T. Mariotti (2000). Irreversible Investment and Learning Externalities. Discussion Paper no. 2003534, CREMAQ, Université des Sciences Sociales, Toulouse, France.

Dixit, A.K. (1980). The Role of Investment in Entry Deterrence. The Economic Journal, 90, 95-106. 
Dixit, A.K. and R.S. Pindyck (1996). Investment under Uncertainty. Princeton University Press, Princeton, NJ. Second printing.

Feller, W. (1971). An Introduction to Probability Theory and Its Applications, volume II (Second ed.). John Wiley \& Sons, New York, NY.

Fudenberg, D. and J. Tirole (1985). Preemption and Rent Equalization in the Adoption of New Technology. The Review of Economic Studies, 52, 383-401.

Fudenberg, D. and J. Tirole (1991). Game Theory. MIT-press, Cambridge, Mass.

Grenadier, S.R. (2000). Game Choices: The Intersection of Real Options and Game Theory. Risk Books, London, UK.

Hendricks, K. , A. Weiss, and C. Wilson (1988). The War of Attrition in Continuous Time with Complete Information. International Economic Review, 29, 663-680.

Hoppe, H.C. (2000). Second-mover Advantages in the Strategic Adoption of New Technology under Uncertainty. International Journal of Industrial Organization, 18, 315-338.

Huisman, K.J.M. (2001). Technology Investment: A Game Theoretic Real Options Approach. Kluwer Academic Publishers, Dordrecht, The Netherlands.

Jensen, R. (1982). Adoption and Diffusion of an Innovation of Uncertain Profitability. Journal of Economic Theory, 27, 182-193.

Jensen, R. (1992a). Dynamic Patent Licensing. International Journal of Industrial Organization, 10, 349-368.

Jensen, R. (1992b). Innovation Adoptation and Welfare under Uncertainty. The Journal of Industrial Economics, 40, 173-180.

Lambrecht, B. and W. Perraudin (2003). Real Options and Preemption under Incomplete Information. Journal of Economic Dynamics and Control, 27, 619-643.

Mamer, J.W. and K.F. McCardle (1987). Uncertainty, Competition and the Adoption of New Technology. Management Science, 33, 161-177.

Mankiw, N.G. and M.D. Whinston (1986). Free Entry and Social Inefficiency. Rand Journal of Economics, 17, 48-58.

Maynard Smith, J. (1974). The Theory of Games and Evolution in Animal Conflict. Journal of Theoretical Biology, 47, 209-221.

Smets, F. (1991). Exporting versus FDI: The Effect of Uncertainty, Irreversibilities and Strategic Interactions. Working Paper, Yale University, New Haven, Conn. 
Stenbacka, R. and M.M. Tombak (1994). Strategic Timing of Adoption of New Technologies under Uncertainty. International Journal of Industrial Organization, 12, $387-411$.

Thijssen, J.J.J. , K.J.M. Huisman, and P.M. Kort (2002). Symmetric Equilibrium Strategies in Game Theoretic Real Option Models. CentER DP 2002-81, Tilburg University, Tilburg, The Netherlands.

Thijssen, J.J.J. , K.J.M. Huisman, and P.M. Kort (2003). The Effect of Information Streams on Capital Budgeting Decisions. Forthcoming in: European Journal of Operational Research.

Tirole, J. (1988). The Theory of Industrial Organization. MIT-press, Cambridge, Mass.

Weeds, H.F. (2002). Strategic Delay in a Real Options Model of R\&D Competition. Review of Economic Studies, 69, 729-747.

Zingales, L. (2000). In Search of New Foundations. The Journal of Finance, 55, $1623-1654$. 